\title{
Atmospheric radioactivity over Tsukuba, Japan: a summary of three years of observations after the FDNPP accident
}

\author{
Yasuhito Igarashi $^{{ }^{*}}$, Mizuo Kajino', Yuji Zaizen ${ }^{1}$, Kouji Adachi $^{1}$ and Masao Mikami ${ }^{1,2}$
}

\begin{abstract}
A severe accident occurred in March 2011 at the Fukushima Dai-ichi nuclear power plant (FDNPP) operated by the Tokyo Electric Power Company (TEPCO), causing serious environmental pollution over a wide range covering eastern Japan and the northwestern Pacific. This accident created a large mark in the atmospheric radionuclide chronological record at the Meteorological Research Institute (MRI). This paper reports the impacts from the FDNPP accident over approximately 3 years in Tsukuba, Ibaraki (approximately $170 \mathrm{~km}$ southwest from the accident site), as a typical example of the atmospheric pollution from the accident. The monthly atmospheric ${ }^{90} \mathrm{Sr}$ and ${ }^{137} \mathrm{Cs}$ depositional fluxes in March 2011 reached approximately $5 \mathrm{~Bq} / \mathrm{m}^{2} / \mathrm{month}$ and $23 \mathrm{kBq} / \mathrm{m}^{2} / \mathrm{month}$, respectively. They are 3-4 and 6-7 orders of magnitude higher, respectively, than before the accident. Sr-90 pollution was relatively insignificant compared to that of ${ }^{137} \mathrm{Cs}$. The ${ }^{137} \mathrm{Cs}$ atmospheric concentration reached a maximum of $38 \mathrm{~Bq} / \mathrm{m}^{3}$ during March 20-21, 2011. After that, the concentrations quickly decreased until fall 2011 when the decrease slowed. The pre-FDNPP accident ${ }^{137} \mathrm{Cs}$ concentration levels were, at most, approximately $1 \mu \mathrm{Bq} / \mathrm{m}^{3}$. The average level 3 years after the accident was approximately $12 \mu \mathrm{Bg} / \mathrm{m}^{3}$ during 2014. The atmospheric data for the 3 years since the accident form a basis for considering temporal changes in the decreasing trends and re-suspension (secondary emission), supporting our understanding of radioCs' atmospheric concentration and deposition. Information regarding our immediate monitoring, modeling, and data analysis approaches for pollution from the FDNPP accident is provided in the Appendices.
\end{abstract}

Keywords: Temporal change, ${ }^{90} \mathrm{Sr},{ }^{137} \mathrm{Cs}$, Atmospheric deposition, Atmospheric concentration, FDNPP accident

\section{Background}

We have conducted observational research on radionuclides in the environment for almost 60 years at the Meteorological Research Institute (MRI) in Japan, ever since the 1950s when the USA, Soviet Union, and others performed vigorous nuclear tests in the atmosphere. The atmosphere is the major medium into which radioactive materials were directly injected by the nuclear tests and accidents, and within it, transport, diffusion, and wet and dry removal of these materials occur. During the nuclear testing era, the major purpose of our research was to clarify the radioactive pollution situation and its major controlling

\footnotetext{
* Correspondence: yigarash@mri-jma.go.jp

${ }^{1}$ Meteorological Research Institute, 1-1 Nagamine, Tsukuba, Ibaraki 305-0052, Japan

Full list of author information is available at the end of the article
}

factors in the atmosphere (Hirose et al. 1986; Katsuragi 1983; Miyake 1954; Miyake et al. 1963, 1975) and hydrosphere (Miyake et al. 1955, 1962, 1988). After the Chernobyl accident, the purpose of the research gradually shifted to obtaining more data about various processes in the atmosphere (Aoyama 1988; Aoyama et al. 1986, 1987, 1991, 2006; Hirose et al. 1993, 2001; Igarashi et al. 1996, 2003, 2009) and hydrosphere (Aoyama 1995, Aoyama and Hirose 2004; Hirose et al. 1999, Hirose and Aoyama 2003; Miyao et al. 2000). Of particular interest in this study, observation of monthly radionuclide deposition (atmospheric total deposition/ radioactive fallout) for ${ }^{90} \mathrm{Sr}$ (half-life, 28.8 years) and ${ }^{137} \mathrm{Cs}$ (half-life, 30.2 years) had continued for 57 years as of April 2014, although the location of the observations moved from Koenji, Tokyo, to Tsukuba in 1980 when the science city was built (Katsuragi 1983). Both radionuclides are 
scientifically important because of their health and environmental impacts (e.g., see U.S. Department of Health and Human Services, Public Health Service, Agency for Toxic Substances and Disease Registry ATSDR2004Cs 2004; U.S. Department of Health and Human Services, Public Health Service, Agency for Toxic Substances and Disease Registry ATSDR2004Sr 2004). We continued collecting and analyzing atmospheric samples after the accident at Tokyo Electric Power Company's (TEPCO) Fukushima Dai-ichi Nuclear Power Plant (FDNPP) in Ohkuma-machi and Futabamachi, Fukushima prefecture $\left(37.42{ }^{\circ} \mathrm{N}, 140.97{ }^{\circ} \mathrm{E}\right)$ in March 2011.

Many authors have attempted to determine the environmental impacts of the FDNPP accident, which have gradually come to light (e.g., Aoyama et al. 2012, 2013; Hirose 2012; Kusakabe et al. 2013; Masson et al. 2011; Masumoto et al. 2012; MEXT 2011a ; MEXT and USDOE 2011; Povinec et al. 2013a, b; Tsumune et al. 2013; Yamamoto et al. 2012; Yoshida and Kanda 2012; Yoshida and Takahashi 2012). We still need to study the following issues from an atmospheric science point of view (Igarashi 2009): (1) primary source terms including emissions inventory and temporal changes (e.g., Chino et al. 2011; Katata et al. 2012, b, 2014; Maki et al. 2013; Stohl et al. 2012; Terada et al. 2012; Winiarek et al. 2012), (2) transport and diffusion (e.g., Masson et al. 2011; Morino et al. 2011; Sekiyama et al. 2015; Stohl et al. 2012; Takemura et al. 2011; Tanaka 2013; Terada et al. 2012), and (3) dry and wet removal (e.g., Adachi et al. 2013; Hirose et al. 1993; Kristiansen et al. 2012), which governed radioactive surface contamination during the early phase of the accident. In addition, the physical and chemical properties of the radioactive materials (e.g., Adachi et al. 2013; Kaneyasu et al. 2012) are important factors that influence the second and third subjects to be investigated. Here, we summarize the observations, present a time series of the atmospheric impacts of the TEPCO FDNPP accident over approximately 3 years in Tsukuba, Ibaraki, Japan, and compare the levels to the situation before the accident as very basic scientific information (Igarashi, 2009). In addition, secondary emissions from contaminated surfaces to the atmosphere (re-suspension; Igarashi 2009) have become important during the later phases. Resuspension comes from contaminated surfaces, terrestrial ecosystems, and open-field burning. These sources have undoubtedly supported atmospheric radionuclides but are not yet well understood and are thus considered briefly. Other information about the accident, related to our immediate monitoring and modeling endeavors and data analysis approaches to short-lived $\gamma$-emitters and ${ }^{89} \mathrm{Sr}$, is summarized in the Appendices.

\section{Methods}

\section{Atmospheric deposition samples}

The monthly atmospheric total deposition/atmospheric fallout has been sampled using a weathering-resistant plastic tray $\left(\right.$ area $\left.=4 \mathrm{~m}^{2}\right)$ installed on a cottage roof in an open field of the MRI in Tsukuba, Ibaraki $\left(36.1^{\circ} \mathrm{N}, 140.1^{\circ} \mathrm{E}\right.$; approximately $170 \mathrm{~km}$ southwest of the FDNPP) since the 1980s. After April 2011, the sample size was reduced to two trays, each $1 \mathrm{~m}^{2}$, which we considered sufficient for the levels present after the FDNPP accident. The collected samples were evaporated and concentrated into a gross quantity with a rotary evaporator (Eyela NE-12) or an evaporating dish, and the samples were saved in a polyethylene safekeeping container. Each evaporated sample, packed in a cylindrical plastic container, was measured for $\gamma$-ray emitting radionuclides $\left({ }^{134} \mathrm{Cs}\right.$ and $\left.{ }^{137} \mathrm{Cs}\right)$ using a Ge semiconductor detector (coaxial-type from ORTEC EG\&G or Eurisys) coupled with a computed spectrometric analyzer (Oxford-Tennelec Multiport or Seiko EG\&G 92x). The precision, accuracy, and quality control of the measurements are described elsewhere (Otsuji-Hatori et al. 1996).

Part of the sample was then stored for future reanalysis. The remaining sample was added to concentrated nitric acid along with $\mathrm{H}_{2} \mathrm{O}_{2}$ and digested in a heating operation. Sr-90 was radiochemically recovered from the obtained sample solution, purified and finally fixed as $\mathrm{Sr}$ carbonate precipitate, an activity measurement source. After the source was left for several weeks to achieve ${ }^{90} \mathrm{Sr}$ and ${ }^{90} \mathrm{Y}$ radioequilibrium, its $\beta$-activity was measured using a low-background $2 \pi$ gas-flow detector (Tennelec LB5100) with P10 gas (Otsuji-Hatori et al. 1996). Within several months after the FDNPP accident, ${ }^{89} \mathrm{Sr}$ (half-life, 50.5 days) from the accident coexisted with ${ }^{90} \mathrm{Sr}$ and affected the $\beta$-activity measurement. To remove the ${ }^{89} \mathrm{Sr}$ influence, we occasionally repeated the $\mathrm{Sr}$ source measurement and evaluated the radioequilibrium between ${ }^{90} \mathrm{Sr}$ and ${ }^{90} \mathrm{Y}$, as well as the decrease in ${ }^{89} \mathrm{Sr}$ activity (see Appendix 2). When required, the influence of the ${ }^{89} \mathrm{Sr}$ activity was subtracted from the $\beta$ activity counts to obtain the ${ }^{90} \mathrm{Sr}$ activity. The activity was always decay-corrected mid-sampling. The detection limit for ${ }^{90} \mathrm{Sr}$ was approximately $7.0 \mathrm{mBq} / \mathrm{sample}$, approximately $3.5 \mathrm{mBq} / \mathrm{m}^{2}$ using a total of $30,000 \mathrm{~s}$ of measurement. For ${ }^{137} \mathrm{Cs}$, the limit was approximately $16.0 \mathrm{mBq} / \mathrm{sample}$, approximately $8.0 \mathrm{mBq} / \mathrm{m}^{2}$ for an average of $120,000 \mathrm{~s}$ of measurement.

\section{Atmospheric radioactive aerosols}

Aerosol samples were collected weekly using a highvolume air sampler (HV; Sibata Scientific Technology Ltd., HV-1000 F) on a quartz fiber filter (Advantech QR100; $203 \mathrm{~mm} \times 254 \mathrm{~mm}$ ) (Igarashi et al. 1999a). During March 2011, the sampling frequency was intensified. 
The flow rate was set at $0.7 \mathrm{~m}^{3} / \mathrm{min}$, and the daily sucked air volume was approximately $1000 \mathrm{~m}^{3}$. After collection, the filters were compressed into pellets using a hydraulic press device. They then underwent conventional $\gamma$-ray spectrometry with Ge detectors as described above. Current detection limits for ${ }^{134} \mathrm{Cs}$ and ${ }^{137} \mathrm{Cs}$ are approximately $9.0 \mathrm{mBq} / \mathrm{sample}\left(1.3 \mu \mathrm{Bq} / \mathrm{m}^{3}\right)$ and $10 \mathrm{mBq} / \mathrm{sample}\left(1.5 \mu \mathrm{Bq} / \mathrm{m}^{3}\right)$ for approximately $1,000,000 \mathrm{~s}$ measurements, respectively.

The filter samples collected before the radioactive plume arrived at Tsukuba were measured at the Kyoto University Research Reactor Institute to achieve lower detection limits and avoid contamination from the FDNPP accident. This was necessary because the Ge detectors, measurement environment, and experimental materials at the MRI were somehow contaminated by the radioactive plume's passage on March 14-15 and 20-23, 2011 (see Appendix 1). To date, radioSr analysis has been performed on only a limited number of aerosol samples collected during March 2011. The results are presented in Appendix 2.

\section{Results and discussion}

Figures 1 and 2 depict the results of the atmospheric ${ }^{90} \mathrm{Sr}$ and ${ }^{137} \mathrm{Cs}$ deposition observations at the MRI for different durations. The temporal changes in monthly radionuclide depositions shown in Fig. 1 include those from the late 1950 s to more recently available data, i.e., after the FDNPP accident. Figure 2 compares the amounts of atmospheric deposition after the FDNPP accident and from the late 2000s. Analyses of ${ }^{90} \mathrm{Sr}$ and ${ }^{137} \mathrm{Cs}$ deposition samples taken 6 and 8 months before the accident are ongoing to control for possible sample contamination at the MRI caused by the accident. Thus, these data are missing in Figs. 1 and 2.

Figure 3 depicts the temporal change in atmospheric activity concentrations of radioCs since March 2011. Before the FDNPP accident, it was difficult to detect ${ }^{137} \mathrm{Cs}$ below about $1 \mu \mathrm{Bq} / \mathrm{m}^{3}$ in the air (the global fallout background level).

Although there were small-scale Japanese nuclear accidents in the 1990s (Igarashi et al. 1999a, 2000; Komura et al. 2000), they did not cause significant marks in the present time series of monthly ${ }^{90} \mathrm{Sr}$ and ${ }^{137} \mathrm{Cs}$ depositions. The effects of the Chernobyl accident that occurred in 1986 were more evident for ${ }^{137} \mathrm{Cs}$ than ${ }^{90} \mathrm{Sr}$ (e.g., Aoyama et al. 1991) as illustrated in Fig. 1. However, the previous maximum ${ }^{137} \mathrm{Cs}$ deposition was two orders of magnitude lower than those caused by the FDNPP accident. Thus, the impact of the FDNPP

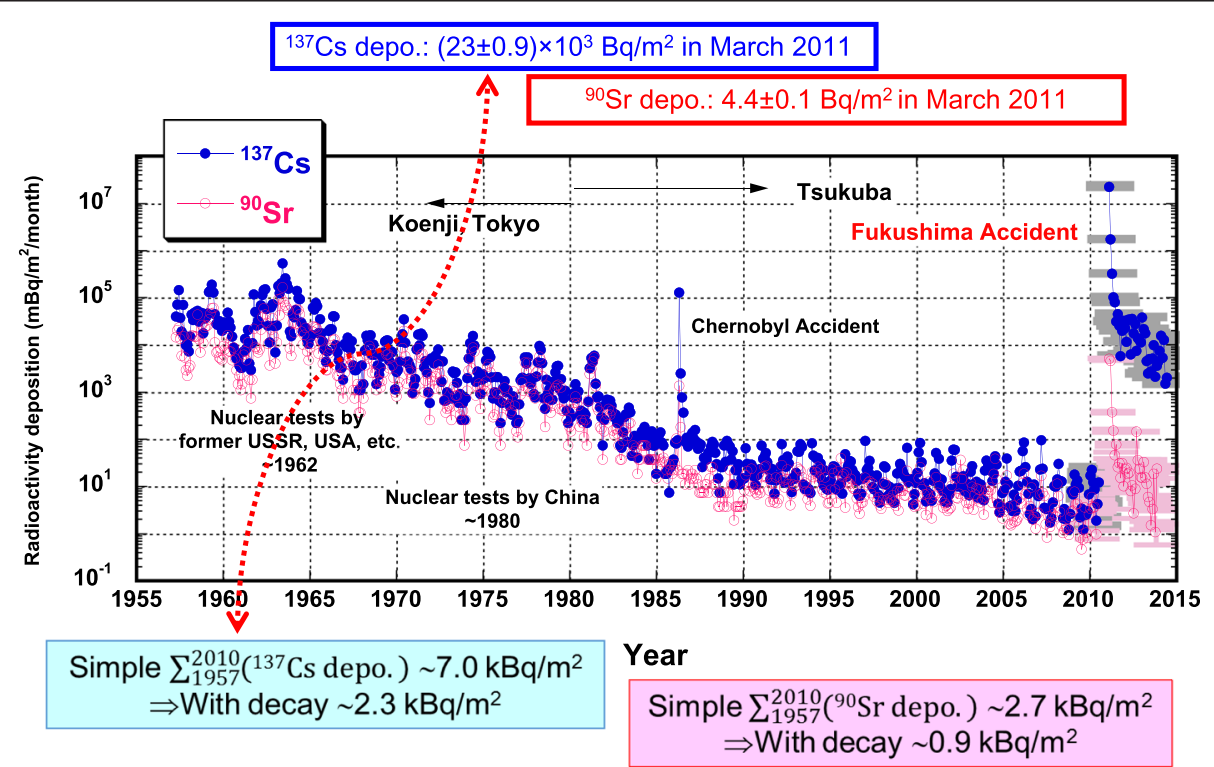

Fig. 1 Sr-90 and ${ }^{137} \mathrm{Cs}$ monthly deposition observed at the Meteorological Research Institute (MRI) from 1957 to 2014. Monthly deposition is expressed in millibecquerel per square meter on a logarithmic scale. Sr-90 and ${ }^{137} \mathrm{Cs}$ analyses from deposition samples taken 6 and 8 months before the accident, respectively, are ongoing to avoid possible sample contamination at the MRI because of the accident. Thus, these data are missing not only in Fig. 1 but also in Fig. 2. The measurement uncertainty $(1 \sigma)$ is shown only for the data obtained after the FDNPP accident and is reasonably small compared to the analytical data. For comparison, uncertainty for the monthly data in 2010 is also given. The effects of atmospheric nuclear bomb tests have been recorded since 1957. Until the Partial Test Ban Treaty (PTBT) became effective in 1963, the USA, Soviet Union, and UK conducted atmospheric tests. France and China continued atmospheric testing until 1974 and 1980, respectively. Since 1981, all the nuclear bomb tests have shifted underground, so additional radioSr and Cs contamination should be negligible. However, the Chernobyl accident in 1986 also affected the time series. The simple summation of the deposition from 1957 to the time before the FDNPP accident (mid-2010) and decay-corrected summations for ${ }^{90} \mathrm{Sr}$ and ${ }^{137} \mathrm{Cs}$ can be compared to the FDNPP-derived deposition 


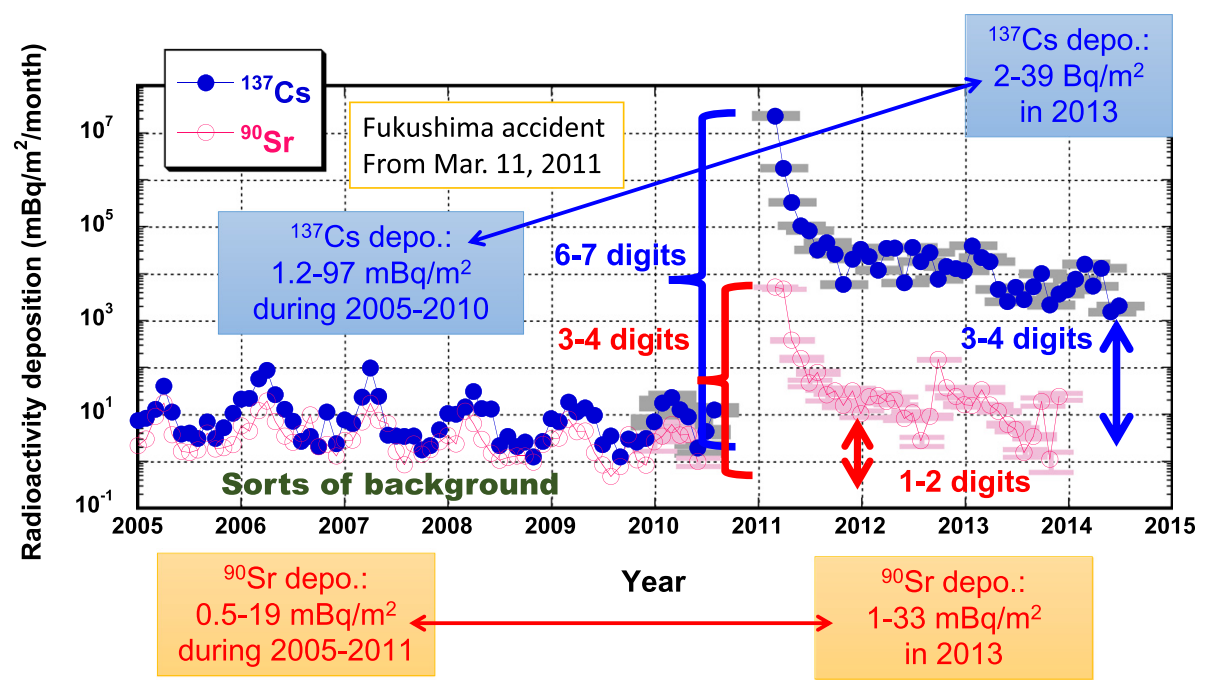

Fig. 2 Monthly ${ }^{90} \mathrm{Sr}$ and ${ }^{137} \mathrm{Cs}$ deposition levels in pre- and post-accident periods. Partial enlargement of Fig. 1. The monthly deposition is expressed in millibecquerel per square meter on a logarithmic scale. The atmospheric depositions of ${ }^{90} \mathrm{Sr}$ and ${ }^{137} \mathrm{Cs}$ in 2013 observed at the MRI were a few orders of magnitude higher than those from 2005 to 2011 before the FDNPP accident. For ${ }^{90} \mathrm{Sr}$ and ${ }^{137} \mathrm{Cs}$, monthly depositions during 2005 to 2010 were $0.5-19 \mathrm{mBq} / \mathrm{m}^{2} / \mathrm{month}$ and $1.2-97 \mathrm{mBq} / \mathrm{m}^{2} /$ month, whereas they were $1-33 \mathrm{mBq} / \mathrm{m}^{2} / \mathrm{month}$ and $2-39 \mathrm{~Bq} / \mathrm{m}^{2} / \mathrm{month}$ in 2013 , respectively

accident was more remarkable than any previous incident in our time series.

Temporal changes in monthly ${ }^{137} \mathrm{Cs}$ atmospheric deposition

The monthly ${ }^{137} \mathrm{Cs}$ deposition in March 2011, when the FDNPP accident occurred, was $23 \pm 0.9 \mathrm{kBq} / \mathrm{m}^{2} /$ month, which is six to seven orders of magnitude higher than the level before the Fukushima disaster (Figs. 1 and 2). Because the pollution source of the FDNPP accident is closer to the observation site $(170 \mathrm{~km})$ than it is to the weapons testing sites and Chernobyl (several thousand kilometers), the spatial representativeness of the MRI data (as an absolute value) is lower.

The cumulative ${ }^{137} \mathrm{Cs}$ deposition at the MRI was $25.5 \mathrm{kBq} / \mathrm{m}^{2} /$ year for the year 2011. The sum of the

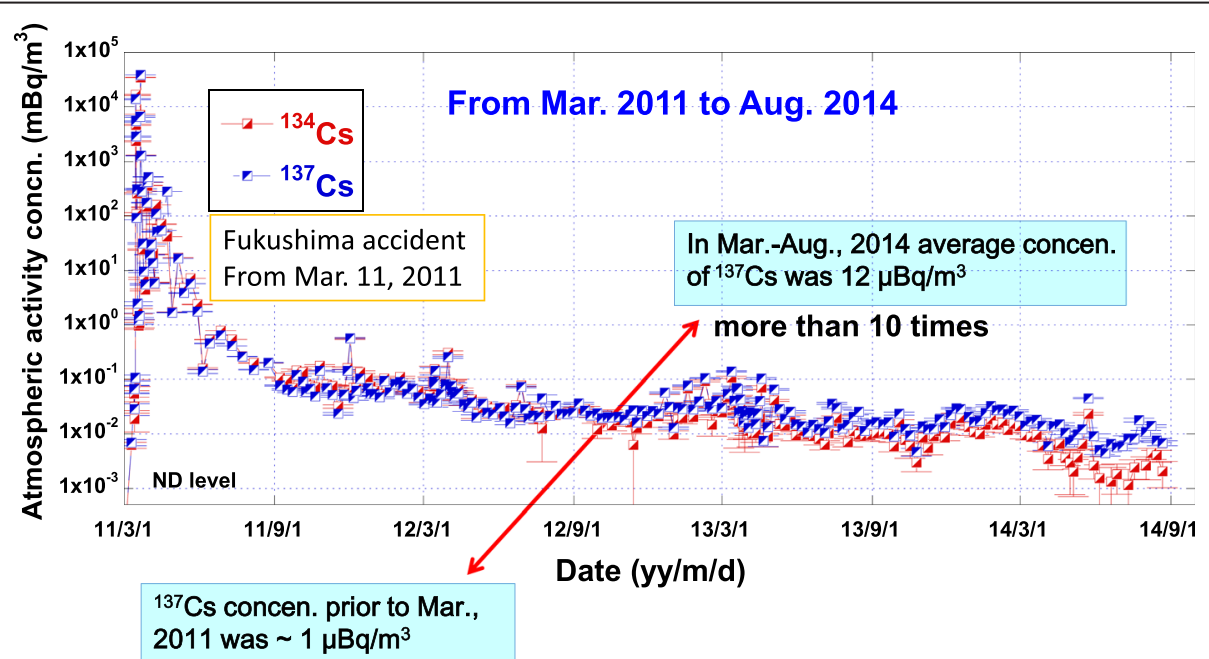

Fig. 3 Temporal change in atmospheric radioCs concentrations at the MRI before and after the FDNPP accident ("Mar.-Aug. 2014"). Activity concentration is expressed in milli becquerel per cubic meter on a logarithmic scale. The measurement uncertainty (1ఠ) is shown. The maximum concentration of $38 \mathrm{~Bq} / \mathrm{m}^{3}$ of ${ }^{137} \mathrm{Cs}$ was observed during March 20-21, 2011. After that, the radioCs concentrations rapidly decreased until fall 2011 when the decrease slowed. The levels before (approximately $\left.1 \mu \mathrm{Bq} / \mathrm{m}^{3}\right)$ and 3 years after the FDNPP accident $\left(12 \mu \mathrm{Bq} / \mathrm{m}^{3} \mathrm{from} \mathrm{March}\right.$ to August 2014) are also compared. A difference of at least one order of magnitude is observed between the concentration level from March to August 2014 and the level before the FDNPP accident 
simple monthly ${ }^{137} \mathrm{Cs}$ depositions from 1957 to mid2010, the time before the Fukushima disaster, is approximately $7.0 \mathrm{kBq} / \mathrm{m}^{2}$ (this figure is thought to contain some error since the pre-1970s data did show individual undefined errors), as shown in Fig. 1. Considering the radioactive decay of the individual monthly ${ }^{137} \mathrm{Cs}$ depositions, this past total contribution represents $2.3 \mathrm{kBq} / \mathrm{m}^{2}$. The FDNPP accident's influence was over ten times larger than that of any past event. Almost the same amount of ${ }^{134} \mathrm{Cs}$ (half-life, 2.1 years) was simultaneously deposited with the ${ }^{137} \mathrm{Cs}$; thus, the total cesium deposition came to more than $50 \mathrm{kBq} / \mathrm{m}^{2}$. This value agrees quite well with figures for the area around Tsukuba in observation mapping provided by the Ministry of Education, Culture, Sports, Science and Technology (MEXT 2011a).

Later, the deposition decreased rapidly, but the monthly ${ }^{137} \mathrm{Cs}$ deposition in 2012 and 2013 ranged from 8-36 and $2-39 \mathrm{~Bq} / \mathrm{m}^{2} /$ month, respectively, where deposition during 2005-2010 had been in the range of 1.2$97 \mathrm{mBq} / \mathrm{m}^{2} / \mathrm{month}$, i.e., three to four orders of magnitude higher. The deposition level at the end of 2013 was still as high as values registered when atmospheric nuclear tests were conducted by China in the 1970s to the early 1980s. The deposition rate slowly decreased in the following years.

\section{Atmospheric concentrations of radioCs}

Figure 3 displays the temporal change in the atmospheric radioCs activity concentrations at the MRI in Tsukuba since the FDNPP accident. The temporal trend shows an abrupt increase (peak) of several orders of magnitude, followed by a rather rapid concentration decrease over a short period (3 to 4 months after the FDNPP accident), with a smaller decreasing rate after. The highest ${ }^{137} \mathrm{Cs}$ atmospheric concentrations $\left(38 \mathrm{~Bq} / \mathrm{m}^{3}\right.$ in a $12 \mathrm{~h}$ sampling period) were registered on March 20-21, 2011, which slightly exceeded the limit stipulated by Japanese regulations and ordinances $\left(30 \mathrm{~Bq} / \mathrm{m}^{3}\right)$. Although the pre-accident activity concentration level was not measured, it had been observed for a short period, from February to April 1997, which includes the time when the Power Reactor and Nuclear Fuel Development Corporation Tokai accident occurred (Igarashi et al. 1999a). The background level was approximately $1 \mu \mathrm{Bq} / \mathrm{m}^{3}$ and did not decrease far below half that value (approximately $0.5 \mu \mathrm{Bq} / \mathrm{m}^{3}$ ) until 2011. The decrease in monthly ${ }^{137} \mathrm{Cs}$ deposition was small during the same period (Igarashi et al. 2003, 2009). Thus, the ${ }^{137} \mathrm{Cs}$ activity concentration level registered during summer 2014 appears at least 10 times higher than that before the accident. During 2011 and 2012, small spikes were recorded from time to time (Fig. 4). In these cases, daily forward trajectory analysis suggested that the polluted air masses were transported from the accident site during the corresponding observation period as shown in the figure. In addition, relatively high concentrations were registered in the winter (Fig. 3). This phenomenon was noted at other places in northern and eastern Japan (Hirose 2013), so there is most likely a common explanation, as described in the literature.

Temporal change in monthly ${ }^{90} \mathrm{Sr}$ atmospheric deposition In contrast to ${ }^{137} \mathrm{Cs}$, the monthly ${ }^{90} \mathrm{Sr}$ deposition in March 2011 was $5.2 \pm 0.1 \mathrm{~Bq} / \mathrm{m}^{2} /$ month. This was approximately $1 / 5000$ the amount of ${ }^{137} \mathrm{Cs}$ deposited in the same month. This deposition was $2-3$ orders of magnitude larger than the level before the FDNPP disaster. The annual ${ }^{90} \mathrm{Sr}$ deposition was $10.6 \mathrm{~Bq} / \mathrm{m}^{2} /$ year during 2011, approximately $1 / 2500$ of the quantity of ${ }^{137} \mathrm{Cs}$ deposited. The simple sum of the monthly ${ }^{90} \mathrm{Sr}$ depositions from 1957 to mid-2010, before the Fukushima disaster, was approximately $2.7 \mathrm{kBq} / \mathrm{m}^{2}$, as shown in Fig. 1. Taking the radioactive decay of the individual monthly ${ }^{90} \mathrm{Sr}$ depositions into account, the sum represents approximately $0.9 \mathrm{kBq} / \mathrm{m}^{2}$. The FDNPP accident's impact on ${ }^{90} \mathrm{Sr}$ was very small. The most extreme monthly ${ }^{90} \mathrm{Sr}$ deposition, recorded during the global fallout era of May 1963 in Tokyo, was $170 \mathrm{~Bq} / \mathrm{m}^{2} /$ month. The FDNPP accident's impact on the monthly ${ }^{90} \mathrm{Sr}$ deposition was less than one-thirtieth of this maximum. Therefore, it is probable that ${ }^{90} \mathrm{Sr}$ pollution over the Kanto Plain from the accident was relatively insignificant; the environmental and health impacts of ${ }^{90} \mathrm{Sr}$ are relatively minor.

In addition, the ${ }^{137} \mathrm{Cs} /{ }^{90} \mathrm{Sr}$ activity ratio fluctuated between approximately 400 and 5000 (Fig. 5), except for some abnormal cases described below. This confirms that the degree of radioSr pollution is relatively insignificant compared to that of radioCs. However, it is still unknown why the ${ }^{137} \mathrm{Cs} /{ }^{90} \mathrm{Sr}$ activity ratio varied so widely despite the radionuclides having a common accident emission source, namely, the FDNPP accident. More discussion on the ${ }^{137} \mathrm{Cs} /{ }^{90} \mathrm{Sr}$ activity ratio is given in Appendix 2 . The reason for the variability is worth studying in the future. The monthly ${ }^{90} \mathrm{Sr}$ deposition recorded in 2012 was $10-31 \mathrm{mBq} / \mathrm{m}^{2} /$ month, whereas during $2005-$ 2010 , it was $0.5-19 \mathrm{mBq} / \mathrm{m}^{2} /$ month, a difference of up to two orders of magnitude.

\section{A ${ }^{90} \mathrm{Sr}$ deposition anomaly in October 2012}

In October 2012, the monthly ${ }^{90} \mathrm{Sr}$ deposition showed a peak of $145 \pm 2 \mathrm{mBq} / \mathrm{m}^{2} /$ month (see the arrow in Figs. 5 and 6), which is $1-2$ orders of magnitude higher than any monthly ${ }^{90} \mathrm{Sr}$ deposition registered that year, and its influence lasted a few months (Fig. 6). This small ${ }^{90} \mathrm{Sr}$ event remains puzzling. By applying forward trajectory analysis and closely examining the precipitation over Tsukuba, we believe that the ${ }^{90} \mathrm{Sr}$ may have come from 




the FDNPP and encountered precipitation on October 7 and 18-19, 2012. However, this increase was not accompanied by a radioCs deposition peak, and the major radionuclide emitted by the FDNPP accident is radioCs, which is inconsistent with FDNPP accident being the source of the October anomaly.

The Japanese Radioactivity Survey data on the Internet were checked, but no consistent data were evident for the corresponding period. In addition, no such anomaly was reported in Europe (Masson 2014, personal communication). Based on the timescale of this contamination, however, the source should be neither very local nor very small. This episode shows some similarities to the case in fall 1995 in Tsukuba (Igarashi et al. 1999b). We also assume unidentified, unreported incidents of burning and/or melting of industrial ${ }^{90} \mathrm{Sr}$ sources in the Far East region as a possible explanation, such as the Algeciras (Spain) incident in 1998 with its ${ }^{137}$ Cs source of



Fig. 5 Activity ratio of ${ }^{137} \mathrm{Cs} /{ }^{90} \mathrm{Sr}$ in monthly depositions since March 2011 at the MRI. The temporal changes do not show a clear decreasing or increasing trend. The arrow shows the month during which an anomalous deposition of ${ }^{90} \mathrm{Sr}$ was observed. Except for the anomaly, the ${ }^{137} \mathrm{Cs} /$ ${ }^{90} \mathrm{Sr}$ activity ratio fluctuated from approximately 150 to 6700 




3.7 TBq (Estevan 2003). Sr-90 is widely used in industrial applications, such as in thickness gauges, and its activity size ranges from $740 \mathrm{MBq}$ to $3.7 \mathrm{GBq}$ in Japan. Because ${ }^{90} \mathrm{Sr}$ is a pure $\beta$-emitter, it is more difficult to determine the sources of its environmental pollution than it is for ${ }^{137} \mathrm{Cs}$.

\section{Decrease in monthly ${ }^{137} \mathrm{Cs}$ deposition after the FDNPP accident}

Although researchers do not agree precisely on the FDNPP radioactivity emission inventory (Chino et al. 2011; Katata et al. 2012, 2012b, 2014; Maki et al. 2013; Stohl et al. 2012; Terada et al. 2012; Winiarek et al. 2012), if the ${ }^{137} \mathrm{Cs}$ emission in March 2011 is assumed to be $10 \mathrm{PBq} / \mathrm{month}$, the deposition/emission ratio (the monthly deposition at the MRI divided by the monthly emissions from TEPCO (2012)) would be approximately $10^{-12}$. If the MRI is included in the so-called "hot spot" area, the deposition could be approximately $100 \mathrm{kBq} / \mathrm{m}^{2}$ (five times larger). This would give a deposition/emission ratio of approximately $10^{-11}$. After March 2011, the ratio is calculated to be in the range of $10^{-10}$ to $10^{-9}$, which appears to be large, if the emission-deposition relation above is correct. We can presume that this excess deposition at the MRI, Tsukuba came from secondary emissions. Thus, Tsukuba can be regarded as representative of a typical suburban area in the Kanto Plain, and the relative trend of temporal changes there can be considered comparable to surface contamination levels for similar geographical domains. The temporal trends (holding time constant) may also be spatially representative, although this potential is limited.

To study the decreasing trend in monthly ${ }^{137} \mathrm{Cs}$ atmospheric deposition caused by the FDNPP accident and to make future projections, a curve was fitted on the temporal trends using multiple components. A drawing software was employed, and the fitting operation was put through 100 iterations, each time changing the initial value so that the calculation results would converge, as shown in Fig. 6. A trinomial exponential function of the form $a \times\left(\mathrm{e}^{-k \times \mathrm{t}}\right)$ was applied to fit the data (where $a$ is a constant and $k$ is an inverted time scale; $\left.\operatorname{Ln} 2 / \mathrm{T}_{1 / 2}\right)$, and the individual half-times (T1, T2, and T3 in Fig. 6) were approximately 5.9 ( $\pm 11 \%)$ days, $16( \pm 18 \%)$ days, and $1.1( \pm 32 \%)$ years, respectively. The relative uncertainty is shown in parentheses. These appear to correspond to the time scale of (1) the reduction in the original FDNPP accident surge (primary emission source), (2) the tropospheric transportation and diffusion of the radioactive plume (equivalent to the removal of radioactive aerosols from the atmosphere), and (3) the emission intensity of re-suspension (secondary emission sources). We posit that some primary radiological release to the atmosphere continues because the FDNPP is not isolated from the neighboring environment (Hirose 2013; TEPCO 2012). The results, then, cannot be assumed to be completely free of primary release. However, the first and second terms can be reasonable estimates corresponding to the primary emission and tropospheric aerosol residence, respectively. 
The second term is almost identical to figures obtained by other recent studies (e.g., Hirose 2012, 2013; Kristiansen et al. 2012). Hirose (2013) analyzed radioCs deposition data obtained during 2011-2012 from several places over the Kanto Plain and Fukushima prefecture, Japan. According to his report, "The apparent half-lives at Ichihara, Tokyo, Utsunomiya, Hitachinaka and Maebashi were 11.9, 10.6, 13.5, 11.5 and $12 \mathrm{~d}$, respectively." Hirose (2012) states that "the residence times of aerosols in the troposphere, which are in the range of 5-30 d, have been determined by natural and anthropogenic radionuclides, which depend on particle size and altitude (Ehhalt, 1973)." Hirose (2012) also argues "the temporal change of the Fukushima-derived ${ }^{137} \mathrm{Cs}$ revealed that the apparent atmospheric residence time of the Fukushima-derived ${ }^{137} \mathrm{Cs}$ in sites within $300 \mathrm{~km}$ from the Fukushima Dai-ichi NPP is about 10 d." This long residence time might reflect the Fukushima radioactive plume's circulation over the Northern Hemisphere, which takes about 20 days (Hernández-Ceballos et al. 2012). As shown in Fig. 8a in the Appendix 1, the third Fukushima plume's arrival over the Kanto Plain was observed from March 28-31, 2011. It was well reconstructed by the aerosol transport model. Other observations over the Kanto Plain also revealed this transport event (e.g., Amano et al. 2012; Haba et al. 2012). However, we cannot clearly determine whether this concentration peak is due to delayed primary emission (e.g., Terada et al. 2012), hemispheric circulation, or a combination of both. This is because the current model simulation uses the emission inventory, which is also based on atmospheric monitoring results (e.g., Terada et al. 2012). Regarding this connection, Kristiansen et al. (2012) investigated the ${ }^{131} \mathrm{I}$ and ${ }^{137} \mathrm{Cs}$ removal times from the atmosphere using global-scale monitoring data. Their estimated ${ }^{137} \mathrm{Cs}$ removal times were in the range of 10.0-13.9 days, which is closer to our present result. They also noted the difference from the typical values of 3-7 days obtained by aerosol model simulations, suggesting that the aerosol transportation models need improvement. We would like to add that the deposition results should be interpreted to reflect not only the surface air but also the air column up to at least the mixed layer. Therefore, the deposition may be affected by large-scale transportation, in contrast to indications obtained from the surface concentration only. For further reference, based on the monthly emission of radioCs until the end of 2011 estimated by TEPCO 2012, the primary emission decrease can be fitted using two exponential laws with half-time constants of 2.3 days $( \pm 2 \%)$ and 48 days $( \pm 23 \%)$.

The third term's half-time of 1.1 years for the MRI data, despite its relatively large associated uncertainty, appears to reveal the total re-suspension of radioCs from contaminated surfaces. This value is too large to correspond to any primary releases from the FDNPP in the early phases. In addition, it agrees with the value for the re-suspension "descending trend" due to the Chernobyl accident reported by Garger et al. (2012), which was 300 days. It was possible to fit a two-term exponential curve to the present ${ }^{137} \mathrm{Cs}$ data by fixing the 1.1-year half-time, obtaining a value of 7.8 days for the first term. When compared with the triple exponential (three-term) model, the fitting distance (defined by the ratio of the calculation to the observation) for the double exponential (two-term) model was larger for elapsed times of 212 months, although there were exceptions. The mean and standard deviation for the two- and three-term fit distances are $2.50 \pm 2.02$ and $1.54 \pm 1.14$, respectively. The medians are 1.82 and 1.09, respectively, suggesting that the three-term model fits better. Although we do not provide an illustration here, we found that fitting with three-term functions for the decrease in monthly ${ }^{90} \mathrm{Sr}$ deposition after the disaster was also possible. Therefore, we preferred fitting with a trinomial exponential function to reproduce the deposition flux of radionuclides from the FDNPP accident. Again, the primary emissions of radioCs to the atmosphere are anticipated to continue at a non-negligible level (less than 7.2 GBq/ month is assumed in TEPCO's latest press release (in Japanese) at http://www.tepco.co.jp/life/custom/faq/images/d150129-j.pdf) because the FDNPP is not isolated from the surrounding environment (Hirose 2013). These delayed primary emissions of approximately $7 \mathrm{GBq}$ are 6-7 orders of magnitude lower than the emissions in March 2011 (e.g., 15 PBq for ${ }^{137}$ Cs; NISA 2011). If the primary emission deposits were delayed in a fashion similar to those from March 2011, recent MRI records after the FDNPP accident would correspondingly be $6-7$ orders of magnitude lower than the peak value caused by the accident (see Fig. 2). Therefore, we consider that the present decrease in the third term reflects secondary emission (re-suspension) trends over the Kanto Plain moderately well. In future, we plan to confirm this by applying different evaluation methods such as transport simulations or others.

\section{Consideration of re-suspension and its persistence}

Currently, there may be interest and concern about how long it will take for the atmospheric radionuclide deposition fluxes to return to pre-FDNPP accident levels (cf. Garger et al. 2012; Hatano and Hatano 2003). Although it seems slightly arbitrary, the monthly ${ }^{137} \mathrm{Cs}$ depositions can be estimated if the fitted curve described above is extrapolated. The result of this extrapolation is illustrated in Fig. 7. This simple estimation shows that more than a decade will likely be required for the activity levels to return to pre-accident levels. Thus, re-suspension (secondary emission to the atmosphere; 


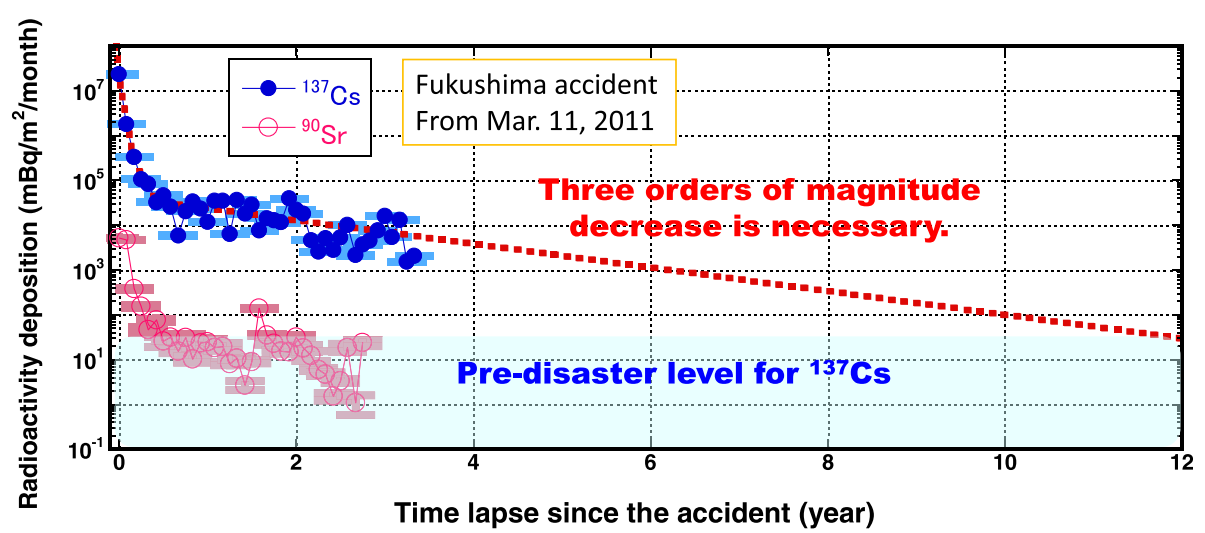

Fig. 7 Future projection for monthly ${ }^{137} \mathrm{Cs}$ deposition level using a trinomial exponential function. The present simple estimation shows that more than a decade would be necessary for the ${ }^{137} \mathrm{Cs}$ atmospheric deposition level to return to pre-accident levels

e.g., Igarashi 2009) must be scrutinized with long-term monitoring. Because it seems natural that radionuclide emission flux would be proportional to surface pollution density, there could be radioCs fluxes several orders of magnitude higher than those measured in Tsukuba in areas nearer the FDNPP site whose Cs surface pollution is several orders of magnitude higher than in Tsukuba. Therefore, elucidating the secondary emission processes of the FDNPP radionuclides remains an imminent scientific challenge, especially for heavily polluted areas. Secondary sources can include soil dust suspension from polluted earth surfaces, emissions from polluted vegetation and forests, and volatilization and release from combustion of polluted garbage and open field burning (e.g., Igarashi 2009). Although the main emission sources are not yet well understood, this elucidation must be performed as soon as possible.

\section{Conclusions}

The authors conducted atmospheric monitoring of airborne radioSr and $\mathrm{Cs}$ and their deposition at the MRI in Tsukuba, Japan. The monitoring period encompasses the FDNPP accident and the subsequent few years. The monthly ${ }^{137} \mathrm{Cs}$ deposition at the MRI was $(23 \pm 0.9) \times$ $10^{3} \mathrm{~Bq} / \mathrm{m}^{2} /$ month in March 2011, which is $6-7$ orders of magnitude higher than pre-accident levels. Almost equal amounts of ${ }^{134} \mathrm{Cs}$ and ${ }^{137} \mathrm{Cs}$ were deposited, causing surface pollution of more than $50 \mathrm{kBq} / \mathrm{m}^{2}$ in Tsukuba in 2011, in close agreement with the Ministry of Education, Culture, Sports, Science and Technology, Japan (MEXT)'s airborne mapping. Deposition of ${ }^{90} \mathrm{Sr}$ was $5.2 \pm 0.1 \mathrm{~Bq} / \mathrm{m}^{2} /$ month in March 2011, which is less than $0.02 \%$ of the total ${ }^{137} \mathrm{Cs}$ deposition in that month. The level of ${ }^{90} \mathrm{Sr}$ deposition was 3-4 orders of magnitude higher than pre-accident levels and did not reach the level registered during the 1960s after nuclear tests; the effects from ${ }^{90} \mathrm{Sr}$ will not be as large as from
radioCs. During 2013, the Fukushima fallout decreased by $3-4$ orders from its magnitude at the time of the accident, yet some becquerel per square meter of monthly deposition continues. This corresponds to the level in the 1970s and early 1980s when China performed atmospheric nuclear tests. During 2013, the ${ }^{137}$ Cs concentration remained at a level of tens of micro becquerel per cubic meter. Because re-suspension (secondary emission) will continue over a long time, it is necessary to monitor its future trends and variability. An apparent decrease in atmospheric radioCs deposition was fitted by trinomial exponentials, giving information regarding the reducing trend of airborne radionuclide persistence through resuspension into the atmosphere. Extrapolation of the decreasing rate suggests that it would take at least a decade for the activity to return to pre-disaster period levels. Further monitoring efforts are essential.

\section{Appendix}

\section{Appendix 1 Temporal changes in radioactive aerosol concentrations and plume transport from the FDNPP accident over Tsukuba in March 2011} Introduction

The heat and blast at the FDNPP accident resulted in the leakage of a huge amount of anthropogenic radionuclides, near the levels of the Chernobyl accident in 1986, into the environment (IAEA 2006; Janžekovič and Križman 2011; NISA 2011), as seen on both the domestic and Northern Hemispheric scale (Hernández-Ceballos et al. 2012; Masson et al. 2011; Takemura et al. 2011; Tanaka 2013). The transport of the radioactive plume and its deposition over the Pacific Ocean (Aoyama et al. 2013; Honda et al. 2012), North America (e.g., Schwantes et al. 2012; Zhang et al. 2011), and Europe (e.g., Masson et al. 2011) as well as within the Japanese 
territories (Hirose 2012; Kinoshita et al. 2011; Morino et al. 2011; Terada et al. 2012; Tsuruta et al. 2014) has been well depicted by many researchers. The pattern of domestic pollution of the land by local fallout was made fairly clear by the creation of a contamination map based on many university investigations (Kinoshita et al. 2011; Tanihata 2013) and airborne surveys by Japan's MEXT and the USA's NASA/DOE (MEXT and USDOE 2011; Sanada et al. 2014; Torii et al. 2013; USDOE 2013). The transport of the radioactive plume and its subsequent deposition over the capital area (the Kanto Plain; Amano et al. 2012; Haba et al. 2012; Tsuruta et al. 2014) has been reported and monitored in Tsukuba (Doi et al. 2013; Kanai 2012). The MRI in Tsukuba suffered almost no electricity outage soon after the earthquake. Thus, aerosol sampling at the observation field continued from before the FDNPP accident through its aftermath. Here, we add our independent observations of the temporal changes in atmospheric radionuclide concentrations over Tsukuba covering all of March 2011, with our specific transport model simulation for reference.

\section{Experiment}

\section{Intensified aerosol sampling}

Aerosol samples were collected onto quartz fiber filters using a high-volume sampler, as described in the body of the paper; the only change was the duration of sampling, from 1 day to $6 \mathrm{~h}$-which was altered as soon as the accident was made public. The total sucked air volume was thus between 250 and $1000 \mathrm{~m}^{3}$.

\section{Activity measurement}

After collection, the filters were treated in the same manner as usual and measured with Ge detectors, as described previously. The filter samples collected before the radioactive plume's arrival at Tsukuba were measured at the Kyoto University Research Reactor Institute (KURRI) to lower the detection limits. This was necessary because the Ge detector and the laboratory environment at the MRI building were contaminated by the radioactive plume on March 14-15 and 20-22, increasing the background levels. Before the compression procedure, portions of the filter were punched out $(33 \mathrm{~mm} \phi \times 4$ pieces $)$, of which one piece was selected for radioSr analysis, as noted in Appendix 2.

\section{Transport modeling}

The Eulerian chemical transport model RAQM2 (Kajino et al. 2012; Adachi et al. 2013; Sekiyama et al. 2015) was used to simulate radioactive plume transport from the FDNPP accident over the Kanto Plain. The JMA/MRI non-hydrostatic meteorological model (NHM; Saito et al. 2007) was used to simulate the meteorological field to calculate the transport and deposition processes of radionuclides using RAQM2. The horizontal domain and its grid resolution $(3 \mathrm{~km})$ were common to both NHM and RAQM2, with 50 vertical layers from the surface up to $22 \mathrm{~km}$ for NHM and 20 layers to $10 \mathrm{~km}$ for RAQM2. The JMA's Meso-Regional Objective Analysis (MANAL), which has a horizontal resolution of $5 \mathrm{~km}$, was used to define the boundary conditions for NHM. The calculated domains cover southern Tohoku and the central part of Honshu. Details of the transport (advection, diffusion, and convective transport) and deposition schemes (dry and wet (in cloud and below cloud, grid-scale and subgrid-scale)) are described in Kajino et al. (2012) and Sekiyama et al. (2015).

We simulated five species of particulate radionuclides (volatile and reactive ${ }^{131} \mathrm{I}\left(\mathrm{I}_{2}\right)$, volatile and nonreactive ${ }^{131} \mathrm{I}\left(\mathrm{CH}_{3} \mathrm{I}\right)$, non-volatile ${ }^{131} \mathrm{I},{ }^{134} \mathrm{Cs}$, and $\left.{ }^{137} \mathrm{Cs}\right)$. We conducted dispersion and deposition simulation of radioCs in two very different forms-hygroscopic submicrons vs. hydrophobic supermicrons-in a previous study (Adachi et al. 2013) and showed that the deposition regions were significantly different. However, because the proportions of hygroscopic and hydrophobic radioCs in emissions have never been estimated, we assumed the hygroscopic submicron aerosols to be the carriers of radionuclides and used dimensions equivalent to the geometric mean of the dry diameter $\mathrm{D}_{g, n, \text { dry }}=102 \mathrm{~nm}$, geometric standard deviation $\sigma_{g}=1.6$, particle density $\rho_{p}=1.83 \mathrm{~g} / \mathrm{cm}^{3}$, and hygroscopicity $\kappa=0.4$ (Petters and Kreidenweis 2007; Adachi et al. 2013). The emission inventories of ${ }^{131} \mathrm{I}$ and ${ }^{137} \mathrm{Cs}$ were taken from Katata et al. (2014). RAQM2 incorporates aerosol dynamic processes, such as nucleation, condensation/volatilization, and coagulation, within and among different aerosol categories, but the size distribution of the aerosols was assumed to remain unchanged in this simulation.

\section{Results and discussion}

\section{Particulate fission products and radioCs}

The detected $\gamma$-emitting radionuclides were ${ }^{99} \mathrm{Mo}-{ }^{99 \mathrm{~m}} \mathrm{Tc}$ (half-life, $65.9-6$ hours), ${ }^{129 \mathrm{~m}} \mathrm{Te}$ (33.6 days), ${ }^{131} \mathrm{I}$ (8.02 days), ${ }^{132} \mathrm{Te}^{132} \mathrm{I}$ (3.20 days-2.3 hours), ${ }^{133} \mathrm{I}$ (20.8 hours), ${ }^{134} \mathrm{Cs}$ (2.07 years), ${ }^{136} \mathrm{Cs}$ (13.2 days), and ${ }^{137} \mathrm{Cs}$ (30.0 years) as shown in Fig. 8a in the Appendix 1. Note that gaseous iodine was not captured by the present sampling. The ${ }^{90} \mathrm{Sr}$ results are also plotted in the figure (for analytical details, please refer to Appendix 2). There were two significant transport events that brought the radioactive plume toward the Kanto Plain in March 2011. One was during March 14-15 and the other occurred during March 20-22. Plume transport is determined by temporal changes in emission 
intensity and the wind field near the ground surface, which have been addressed by many authors (e.g., Katata et al. 2012, 2014; Morino et al. 2011; Terada et al. 2012). The releasing sources are attributed to a venting operation at an individual reactor vessel, reactor core damage, buildings damaged by a hydrogen explosion, and continuous release through a reactor building (see, e.g., TEPCO 2012; Katata et al. 2014). The activity concentrations of these radionuclides were consistent with those described in previous reports regarding Tsukuba (e.g., Doi et al. 2013; Kanai 2012). The March 7-12, 12-13, 13, and 13-14 samples exhibited detectable levels of radioCs and ${ }^{131} \mathrm{I}$, for which we cannot totally rule out the possibility of sample contamination despite their measurement at KURRI. The two events exhibited different radionuclide compositions, reflecting different source at the accident site. Although the ${ }^{134} \mathrm{Cs} /{ }^{137} \mathrm{Cs}$ ratio was unity for both transport events, the activity ratios were ${ }^{131} \mathrm{I} /$ ${ }^{137} \mathrm{Cs} \approx 5$ and ${ }^{132} \mathrm{Te} /{ }^{137} \mathrm{Cs} \approx 8$ during the first event and ${ }^{131} \mathrm{I} /{ }^{137} \mathrm{Cs} \approx 2.5$ and ${ }^{132} \mathrm{Te} /{ }^{137} \mathrm{Cs} \approx 1$ during the second event. Te-132 was significant during the first transport event. Because the melting point of metallic Te is $450{ }^{\circ} \mathrm{C}$, whereas that of Cs is only $28{ }^{\circ} \mathrm{C}$, the finding may suggest a higher temperature for the source in the earlier phase. For comparison, ${ }^{90} \mathrm{Sr}$ data are included in Fig. 8a in the Appendix 1; the details of the measurements are given in Appendix 2.

After the FDNPP accident, unlike in Chernobyl, no radioRu was found (Aoyama et al. 1986, 1987). This may be because of the different accident scenarios; the melting temperature of metallic $\mathrm{Ru}$ is very high (approximately $2500{ }^{\circ} \mathrm{C}$ ).

Another notable point is the magnitude of the concentration drop between the first and second plume events. RadioCs and ${ }^{132} \mathrm{Te}$ concentrations were $4-5$ orders of magnitude lower for the second plume than the concentration peaks, and those for ${ }^{131} \mathrm{I}$ were $2-3$ orders of magnitude lower. This difference appeared to be caused by either the re-suspension of radiol or the contamination of our materials and instruments. The latter seems unlikely, however, because the filter samples were treated identically and the maximum contamination levels would be those found for the March 7-14 samples (measured at the KURRI). We gave sufficient attention to reducing contamination during sampling and sample handling. Nevertheless, the entire environment was contaminated, and therefore, it was difficult to avoid entirely. In any case, the volatile nature of iodine (the boiling point of $\mathrm{CH}_{3} \mathrm{I}$ is $42{ }^{\circ} \mathrm{C}$, while the melting point of $\mathrm{I}_{2}$ is $113{ }^{\circ} \mathrm{C}$ ) is likely part of the cause. Therefore, immediate re-suspension of radioI should be given more attention. This is briefly addressed below.

\section{Transport model simulation}

The aerosol simulation model captures the events that transported the radioactive plume to the Kanto Plain very well (see Fig. 8b and 9 in the Appendix 1). The transport of the plume from the southern Tohoku district is not considered very exceptional (the MRI is approximately $170 \mathrm{~km}$ southwest from the accident site). Aoyama et al. (1999) and Igarashi et al. (1999a) analyzed the radioactive plume over the Kanto Plain from the earlier PNC accident in Tokai, Ibaraki, in 1997. Igarashi et al. (2000a,b) conducted continuous observations at the MRI of ${ }^{85} \mathrm{Kr}$, of which the local source was the Tokai nuclear fuel reprocessing plant approximately $60 \mathrm{~km}$ northeast of Tsukuba. They noted the incidence of plume transport from a point source in northern Ibaraki over the Kanto Plain with a northeasterly wind, a prevalent weekly wind pattern occurring during the spring in Japan. Similar meteorological situations appeared to occur on March 14-15 and March 20-22, 2011 over the Kanto Plain. Notably, the drop in activity concentration between the plume advections is evident in the simulation results ( Fig. $8 \mathrm{~b}$ and $\mathrm{c}$ in the Appendix 1) despite only primary emissions coming from the FDNPP accident. The reality of the observations differed from the simulations (Fig. 8a in the Appendix 1). As described above, contamination in the observation procedures cannot be totally ruled out, but by coupling the model and observations, it is possible to evaluate the immediate resuspension of the atmospheric Fukushima radionuclides (see section below).

Finally, we argue that aerosol transport modeling is an indispensable tool for the assessment of accident effects. However, many uncertainties remain, especially concerning the emission inventory, wet and dry deposition, and cloud processes. Data and information are collected to improve the transport model schemes, and comparison of different models has been performed to contribute to an accurate evaluation of the source term and transport and deposition processes (SCJ 2014).

\section{Estimation of immediate re-suspension factor}

The quantity of the deposited radionuclides that could return again to the air (re-suspension) is notable. Maximum re-suspension is known to occur just after radioactive plume passage (hereafter, we call this immediate re-suspension). Thus, as a primary approach, immediate re-suspension factors were roughly estimated with modeled amounts deposited in the Kanto Plain by the first plume and the observed minimum activity concentration between the two plume events, i.e., March 17 09JST to March 20 09JST. We assumed mass closure between resuspension from the contaminated surface and outflow by horizontal advection and turbulence vertical mixing as below. 

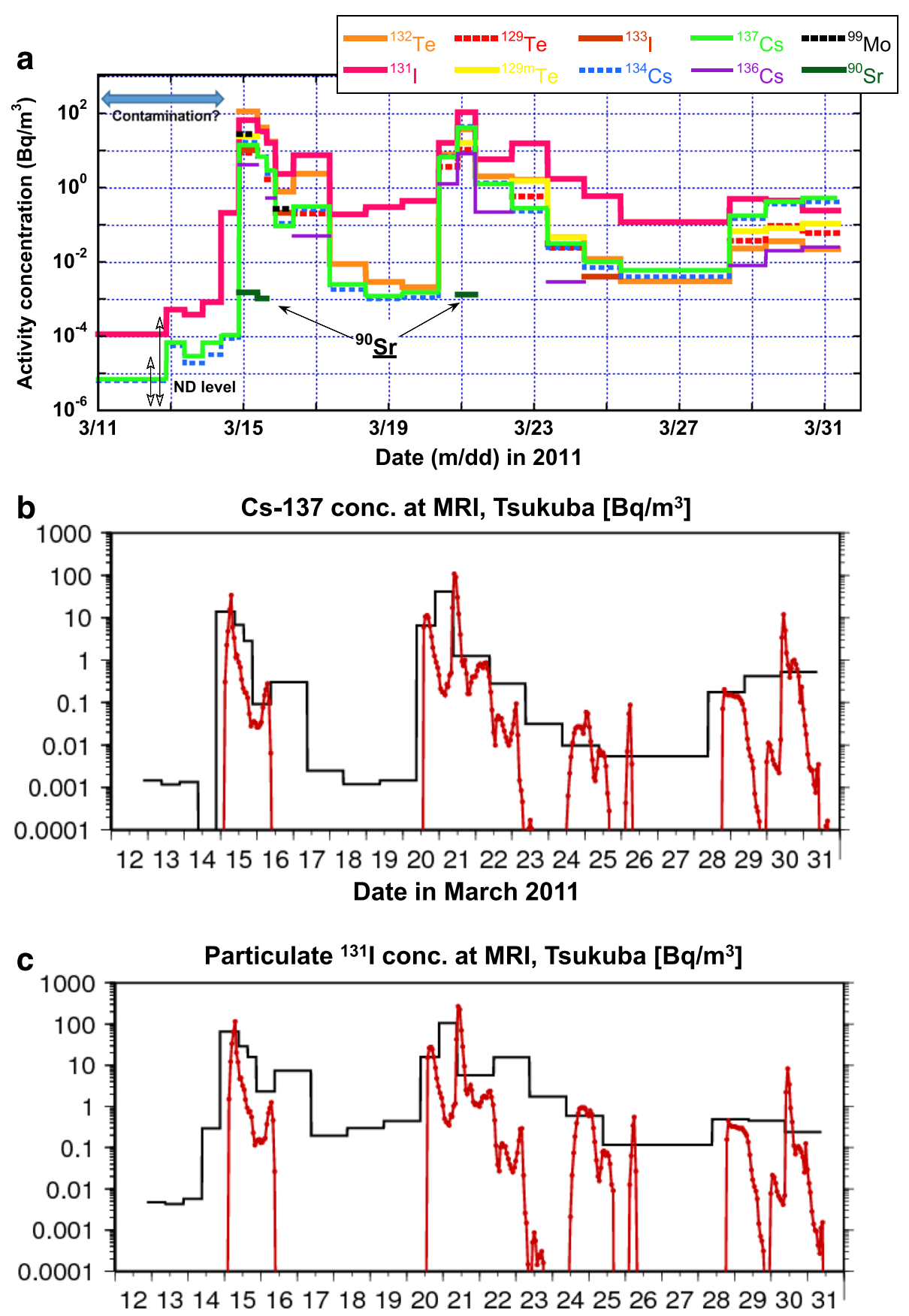

\section{Date in March 2011}

Fig. 8 Atmospheric activity concentrations of radionuclides from the FDNPP accident in March 2011. a Observed data from filter samples collected at the MRI, Tsukuba, Japan; $\mathbf{b}$ comparison of observed (black) and simulated results (red) for ${ }^{137} \mathrm{Cs}$; and $\mathbf{c}$ similar to $\mathbf{b}$ but for particulate ${ }^{131} \mathrm{I}$. The abscissa is expressed in dates in March 2011 and is labeled at the start of the day in $\mathbf{a}$ and the middle of the day in $\mathbf{b}$ and $\mathbf{c}$. Contamination of the filter samples cannot be totally ruled out for the period before March 14 in $\mathbf{a}$, which is depicted by the left-right pointing double arrow

The continuity equation is expressed as

$$
\partial C / \partial t=\nabla\left(\boldsymbol{K}_{\mathrm{dif}} \nabla C\right)-\nabla(\boldsymbol{U} C)-\lambda C+\Phi
$$

in which $C$ is concentration, $\boldsymbol{K}_{\text {dif }}$ indicates threedimensional diffusion terms, $\boldsymbol{U}$ denotes the wind field, $\lambda$ is the decay constant, and $\Phi$ is a re-suspension term for individual radionuclides. On the other hand, the concentration increase in one unit of time from re-suspension is expressed as

$$
\Delta C / \Delta t=\Phi=k_{i} \times D_{i} \times(\Delta x \Delta y / \Delta x \Delta y \Delta z),
$$



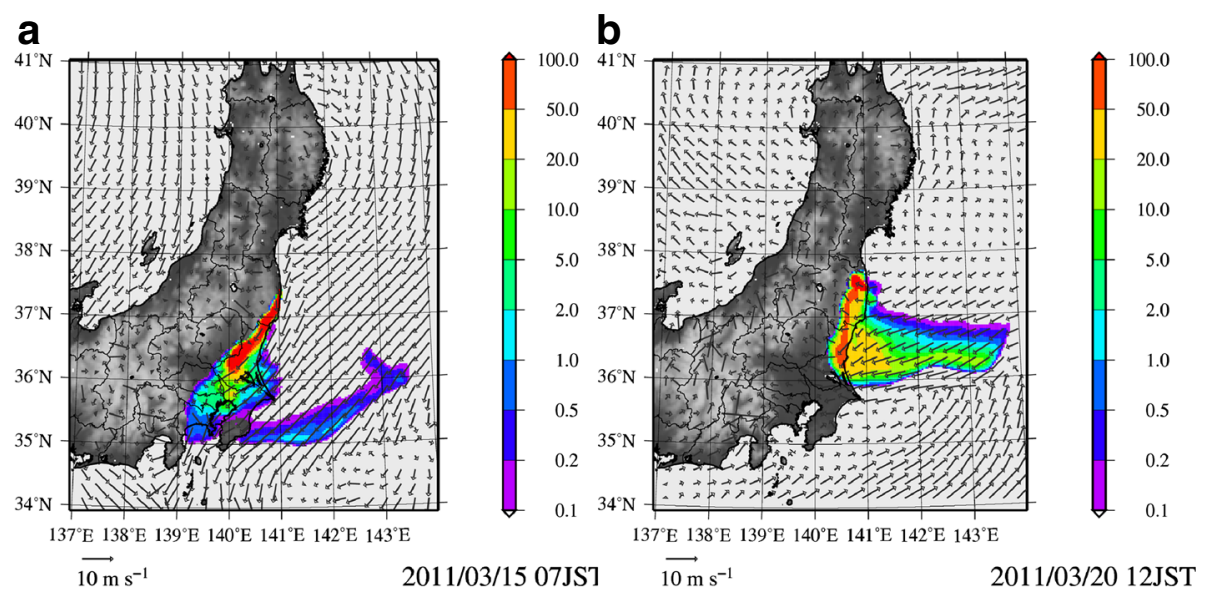

Fig. 9 Radioactive plume transport from the FDNPP accident in the Kanto Plain in March 2011. a On March 15 07JST and b on March 20 12JST. The figures show the simulated surface ${ }^{137} \mathrm{Cs}$ concentration in shaded colors with the model topography in grayscale

in which $k_{i}$ and $D_{i}$ are a re-suspension factor $(/ \mathrm{s})$ and surface contamination $\left(\mathrm{Bq} / \mathrm{m}^{2}\right)$ for individual radionuclides, respectively. Also, $\Delta \mathrm{x}, \Delta \mathrm{y}$, and $\Delta \mathrm{z}$ are the horizontal and vertical lengths of the space where the mass closure is obtained.

We can disregard radioactive decay, horizontal diffusion, and convective wind. Balancing the mass between inflow and outflow, we finally obtain the following relationship:

$$
\begin{aligned}
\left(k_{i} \cdot D_{i}\right) /(\Delta z)= & \left(\Delta K_{z} / \Delta z\right) \times(\Delta C / \Delta z)+(\Delta u / \Delta x \\
& +\Delta v / \Delta y) \times C_{i}
\end{aligned}
$$

in which $i$ indicates the radionuclides, namely, ${ }^{137} \mathrm{Cs}$ and ${ }^{131} \mathrm{I} ; D_{i}$ indicates the modeled total (gas + aerosol) cumulative deposition $\left(\mathrm{Bq} / \mathrm{m}^{2}\right)$ by March 17 09JST; $k_{i}$ is the re-suspension factor $\left(\mathrm{s}^{-1}\right) ; \boldsymbol{U}$ and $K_{z}$ are the modeled space- and time-averaged horizontal wind speed $(\mathrm{m} / \mathrm{s})$ and vertical turbulent diffusivity $\left(\mathrm{m}^{2} / \mathrm{s}\right)$, respectively; $C_{i}$ indicates the time-averaged observed concentrations of the radionuclides $\left(9.75 \times 10^{-4}\right.$ and $3.14 \times 10^{-1} \mathrm{~Bq} / \mathrm{m}^{3}$ for ${ }^{137} \mathrm{Cs}$ and ${ }^{131} \mathrm{I}$, respectively); and $\Delta \mathrm{x}, \Delta \mathrm{y}$, and $\Delta \mathrm{z}$ are the horizontal and vertical distances in space over which the above mass closure is obtained. To obtain the horizontal and vertical gradient terms on the right-hand side of the equation, the concentrations outside the space are assumed to be zero (no inflow into the space).

The re-suspension factors for ${ }^{137} \mathrm{Cs}$ and ${ }^{131} \mathrm{I}$ are $7.0 \times$ $10^{-6} / \mathrm{s}$ and $5.3 \times 10^{-4} / \mathrm{s}$, respectively, for the smallest volume of the RAQM2 model grid $(\Delta x=3 \mathrm{~km}, \Delta y=$ $3 \mathrm{~km}$, and $\Delta \mathrm{z}=100 \mathrm{~m})$. Those for ${ }^{137} \mathrm{Cs}$ and ${ }^{131} \mathrm{I}$ varied from $1.6 \times 10^{-6} / \mathrm{s}$ to $1.5 \times 10^{-5} / \mathrm{s}\left(6.1 \times 10^{-6} / \mathrm{s}\right.$ on average) and from $5.3 \times 10^{-4} / \mathrm{s}$ to $1.3 \times 10^{-3} / \mathrm{s}\left(4.6 \times 10^{-4} / \mathrm{s}\right.$ on average), respectively, for the various horizontal spaces plus neighboring zero, one, or two RAQM2 grids from the grid where the MRI is located (i.e., $\Delta x, \Delta y=3$,
9, or $15 \mathrm{~km}$ ) and vertical spaces plus zero, one, or two RAQM2 grids from the bottom $(\Delta z=100,200$, or $400 \mathrm{~m})$.

In summary, the immediate re-suspension factors $k_{i}$ of ${ }^{137} \mathrm{Cs}$ and ${ }^{131} \mathrm{I}$ are estimated to be on the order of $10^{-6}$ $10^{-5} / \mathrm{s}$ and $10^{-4}-10^{-3} / \mathrm{s}$, respectively, and that of ${ }^{131} \mathrm{I}$ is approximately two orders of magnitude larger than that of ${ }^{137}$ Cs. These values are converted correspondingly, often quoting the concentration ratio over the contaminated surface as follows: $5.8 \times 10^{-6}-1.7 \times 10^{-5}$ and $4.4 \times$ $10^{-4}-1.3 \times 10^{-3} / \mathrm{m}$ ) for ${ }^{137} \mathrm{Cs}$ and ${ }^{131} \mathrm{I}$, respectively. The present data do not display the large deviation hitherto reported (e.g., $10^{-6}-10^{-4} / \mathrm{m}$; Maxwell and Anspaugh 2011). Because those values are based on rough assumptions, further studies based on surface flux measurements need to be conducted to more accurately estimate the re-suspension factors.

\section{Appendix 2 RadioSr in the aerosol samples collected during March 2011 Introduction}

There are several reports containing estimates of the radioactive contamination from the FDNPP accident, presented in the form of mapped images produced from the results of investigations of radionuclides in the soil (e.g., MEXT 2011a ; Sanada et al. 2014; Torii et al. 2013) and in the form of air dose rate figures produced from aircraft observations. Among the radionuclides, radioSr is an important indicator of contamination. The former Nuclear and Industrial Safety Agency (NISA) in Japan reported the following emission estimates within the atmosphere: ${ }^{89} \mathrm{Sr}$ (half-life, 50.5 days) as $2.0 \times 10^{15} \mathrm{~Bq}$ and ${ }^{90} \mathrm{Sr}$ (half-life, 28.8 years) as $1.4 \times 10^{14} \mathrm{~Bq}$ (NISA 2011). Nevertheless, there have been no reports on ${ }^{89} \mathrm{Sr}$ and ${ }^{90} \mathrm{Sr}$ in air samples because of analytical difficulty. The detection of nine different $\gamma$-emitting radionuclides, including ${ }^{99} \mathrm{Mo}$, is described in Appendix 1 . However, ${ }^{89} \mathrm{Sr}$ 
and ${ }^{90} \mathrm{Sr}$ emit no $\gamma$-rays with their radioactive decay, making it impossible to determine their presence by $\gamma$ spectrometry. To evaluate their radioactive pollution levels, the aerosol components were radiochemically extracted from the HV filter sample to analyze the radioSr and assess the emission ratios of ${ }^{137} \mathrm{Cs},{ }^{89} \mathrm{Sr}$, and ${ }^{90} \mathrm{Sr}$.

\section{Experiment}

\section{Sub-HV filter sample for $\mathrm{Sr}$ analysis}

HV filter samples from the $\gamma$-spectrometry measurements noted earlier were used for the radioSr analysis. Approximately $2 \%$ of the filter area was punched out (as circles) and provided for this analysis, which was performed on sub-filter samples collected during March 2011 (Table 1 in the Appendix 2).

\section{Analysis of radioSr}

To dissolve the aerosols on the filter, $100-200 \mathrm{ml}$ of concentrated nitric acid was added and heated on a $200{ }^{\circ} \mathrm{C}$ hotplate, then $1-5 \mathrm{ml}$ of hydrogen peroxide solution was added to accelerate the decomposition of any organic matter. This was followed by further thermolysis for more than an hour. The obtained solution was subjected to separation, which was conducted through radiochemical analysis comprising several precipitation separations, such as oxalate, fuming nitric acid, hydroxide, carbonate, and barium chromate precipitations. The last separation was repeated twice, which allowed the $\mathrm{Sr}$ fraction to be freed from radioBa and $\mathrm{Ra}$ isotopes. The final strontium carbonate deposit was $\beta$-counted with the low-background $2 \pi$ gas-flow counter described earlier (Tennelec LB5100).

\section{Estimating the activity ratio of ${ }^{89} \mathrm{Sr}$ and ${ }^{90} \mathrm{Sr}$}

The atmospheric aerosol sample contained ${ }^{89} \mathrm{Sr}$ and ${ }^{90} \mathrm{Sr}$, indicating that the total $\beta$-activity must be deconvoluted. The measurement sensitivity of the gas-flow counter was confirmed for possible energy independence; therefore, the temporal change in the $\beta$-counting rate of a purified ${ }^{90} \mathrm{Sr}$ (maximum $\beta$-ray energy $0.546 \mathrm{MeV}$ ) source and ${ }^{90} \mathrm{Y}$ (maximum $\beta$-ray energy $2.24 \mathrm{MeV}$ ) growth from the parent nuclide was observed in five specimens of the MRI reference fallout samples (Otsuji-Hatori et al. 1996) that contained no ${ }^{89} \mathrm{Sr}$. The following equation was then applied to find the counting efficiency of ${ }^{90} \mathrm{Sr}$ and ${ }^{90} \mathrm{Y}$ :

$$
N_{\text {total }}=A_{\text {Sr-90 }} \times m_{1}+A_{Y-90} \times\left(1-\mathrm{e}^{-\lambda t}\right) \times m_{2} .
$$

$N_{\text {total }}$ is the total counting rate (cpm); $A$ stands for each nuclide's $\beta$-activity ( $\mathrm{dpm}) ; \lambda$ is the decay constant of ${ }^{90} \mathrm{Y} ; t$ is the elapsed time; and $\mathrm{m}_{1}$ and $\mathrm{m}_{2}$ are the counting efficiencies of ${ }^{90} \mathrm{Sr}$ and ${ }^{90} \mathrm{Y}$, respectively. The $\beta$ ray energy emitted by ${ }^{90} \mathrm{Y}$ is approximately 4 times that of ${ }^{90} \mathrm{Sr}$, and the average values of $m_{1}$ and $m_{2}$ from the five specimens were $27.3 \pm 1.8 \%$ and $24.8 \pm 3.7 \%$, respectively.
Table 1 Temporal variation of ${ }^{90} \mathrm{Sr}$ activity concentration in the air over Tsukuba

\begin{tabular}{|c|c|c|}
\hline $\begin{array}{l}\text { Sampling start date } \\
\text { and time (JST) }\end{array}$ & $\begin{array}{l}\text { End date and } \\
\text { time (JST) }\end{array}$ & $\begin{array}{l}{ }^{90} \mathrm{Sr} \text { activity concentration } \\
\left(\mathrm{mBq} / \mathrm{m}^{3}\right)\end{array}$ \\
\hline March $1221 \mathrm{pm}$ & March $139 \mathrm{am}$ & nd \\
\hline March 1321 pm & March 149 am & nd \\
\hline March 149 am & March 1421 pm & nd \\
\hline March 1421 pm & March 159 am & $1.50 \pm 0.13$ \\
\hline March 159 am & March 1515 pm & $1.04 \pm 0.095$ \\
\hline March 1515 pm & March 1521 pm & nd \\
\hline March 1521 pm & March $169 \mathrm{am}$ & nd \\
\hline March 169 am & March 178 am & nd \\
\hline March 179 am & March 188 am & nd \\
\hline March $188 \mathrm{am}$ & March 199 am & nd \\
\hline March 199 am & March 208 am & nd \\
\hline March 209 am & March 2021 pm & nd \\
\hline March 2021 pm & March 219 am & $1.32 \pm 0.13$ \\
\hline March $219 \mathrm{am}$ & March 229 am & nd \\
\hline March 229 am & March 238 am & nd \\
\hline March 239 am & March 249 am & nd \\
\hline March 249 am & March 259 am & nd \\
\hline March 259 am & March 289 am & nd \\
\hline March 289 am & March $299 \mathrm{am}$ & nd \\
\hline March $299 \mathrm{am}$ & March 309 am & nd \\
\hline
\end{tabular}

Although the "nd" measurements change, depending mainly on the sample volume, the average level was approximately $0.2 \mathrm{mBq} / \mathrm{m}^{3}$ nd not detected

There were no statistically significant differences. Thus, the $\beta$-activities of radioSr were interpreted to have the same counting efficiency regardless of the $\beta$-energy. The activity ratio of ${ }^{89} \mathrm{Sr}$ and ${ }^{90} \mathrm{Sr}$ was elucidated from the value traced back to the date of sample collection as well as the fixed date when the strontium carbonate precipitated. The activity was always decay corrected in the middle of the sampling time. The current detection limit for radioSr in air at that time was approximately $230 \mu \mathrm{Bq} / \mathrm{m}^{3}$.

\section{Results and discussion}

\section{Estimation of ${ }^{90} \mathrm{Sr}$ in the aerosol sample}

We will now quantify and describe the radioSr found in the air over Tsukuba. The radioactivity in Tsukuba indicated a two-fold concentration increase in March 2011, as shown in Fig. 8 in the Appendix 1. The amount of radioSr in the sample was smaller than what was anticipated based on past experience (e.g., Aoyama et al. 1991). ${ }^{90} \mathrm{Sr}$ was unable to be detected except when plume transport occurred. From March 149 pm (JST) to March 159 am, from March 159 am to 3 pm, and March 209 pm to March $219 \mathrm{am}$, the results were $1.5 \pm 0.13,1.0 \pm 0.10$, and $1.3 \pm 0.13 \mathrm{mBq} /$ $\mathrm{m}^{3}$, respectively. For the other samples, the radioSr was 
lower than the detection limits (Table 1 in the Appendix 2). The ${ }^{90} \mathrm{Sr}$ activity results shown here were calculated based on $\beta$-counts made long enough after the events that the contribution of ${ }^{89} \mathrm{Sr}$ could be negligible (less than $5 \%$ of ${ }^{90} \mathrm{Sr}$ activity). For example, we waited at least 200 days after chemical separation (separation was performed after December 2011). The accompanying uncertainty was estimated from the average of the relative $\beta$-count uncertainties in the five latest individual measurements.

The activity ratio of ${ }^{137} \mathrm{Cs} /{ }^{90} \mathrm{Sr}$ in the aerosol samples, which was in the range of 4700-23,000, is very large compared with the activity ratio of radioactive fallout, which was 1.63 during the 1960-1970s; this indicates a clear difference in the data before and after the FDNPP accident. Furthermore, the MRI's estimated ${ }^{137} \mathrm{Cs} /{ }^{90} \mathrm{Sr}$ ratio for the Chernobyl radionuclides in May 1986 in Japan was 96 (Aoyama et al. 1991), which indicates that the Fukushima radionuclide composition was dominated by radioCs. In the activity peak on March 14-15, the ratio was 47006000, and the peak on March 20-21 was 23,000 times higher with ${ }^{137} \mathrm{Cs}$, which also shows that the composition of the radioactive plume differed between the earlier and later dates during the course of the FDNPP accident.

The measured ${ }^{137} \mathrm{Cs} /{ }^{90} \mathrm{Sr}$ activity ratio in Tsukuba was more than 40 times higher than the emission assessment by NISA 2011 for the FDNPP accident $\left({ }^{137} \mathrm{Cs}:{ }^{90} \mathrm{Sr}=15\right.$ : 0.14). The IAEA (2006) had estimated that the amount of ${ }^{90} \mathrm{Sr}$ emitted (approximately $10 \mathrm{PBq}$ ) for the Chernobyl accident was only $12 \%$ that of ${ }^{137} \mathrm{Cs}$ (approximately $85 \mathrm{PBq}$ ), yet in reality, the atmosphere/precipitation observations in Japan showed approximately the amount of ${ }^{90} \mathrm{Sr}$ to be only $1 / 100$ that of ${ }^{137} \mathrm{Cs}$ (Aoyama et al. 1991), indicating that less than $1 / 10$ of the emitted ${ }^{90} \mathrm{Sr}$ was transported. Thus, the $8000 \mathrm{~km}$ long-range transportation from Chernobyl produced the radionuclide separation. With that in mind, it could be possible that fractionation
Table 2 Curve fitting results with assumed ${ }^{89} \mathrm{Sr}$ over ${ }^{90} \mathrm{Sr}$ activity ratio

\begin{tabular}{|c|c|c|c|}
\hline \multicolumn{2}{|c|}{ March 14-15, 2011} & \multicolumn{2}{|c|}{ March 20-21, 2011} \\
\hline${ }^{89} \mathrm{Sr}:{ }^{90} \mathrm{Sr}$ & $\sigma$ & ${ }^{89} \mathrm{Sr}:{ }^{90} \mathrm{Sr}$ & $\sigma$ \\
\hline $9: 0.14$ & 0.3356 & $8: 0.14$ & 0.4550 \\
\hline $10: 0.14$ & 0.3340 & $9: 0.14$ & 0.4165 \\
\hline $11: 0.14$ & 0.3493 & 10:0.14 & 0.5432 \\
\hline 12:0.14. & 0.3795 & $11: 0.14$ & 0.5869 \\
\hline
\end{tabular}

The results for two air filter samples collected in March 2011. The minimum standard deviation $\sigma$ suggests the best estimate

caused by particle size deviation (Hirose et al. 1993) occurred in the FDNPP plume. The plume was transported less than a few hundred kilometers in the present case, but fractionation could be very effective.

\section{${ }^{89} \mathrm{Sr} /{ }^{90} \mathrm{Sr}$ activity ratio}

The emissions estimated by NISA 2011 showed that the ${ }^{89} \mathrm{Sr}$ proportion was 14 times higher than that of ${ }^{90} \mathrm{Sr}$ after the nuclear accident, which indicated that the radioactivity estimate would be $1 / 3$ that of ${ }^{90} \mathrm{Sr}$ after a year. The results from the aerosol sample observations suggest the presence of ${ }^{89} \mathrm{Sr}$; therefore, the temporal change in the $\beta$-counts was fitted based on emission estimates by the former NISA $\left({ }^{89} \mathrm{Sr}:{ }^{90} \mathrm{Sr}=2: 0.14\right)$. Figure 10 in the Appendix 2 shows the fitted results of the aerosol sample measurements for March 14-15. As shown in the figure, the sample counting values exhibited a large decay after 40 days of fixation as strontium carbonate, which indicates that the amount of coexisting ${ }^{89} \mathrm{Sr}$ was relatively large. Therefore, appropriately different ratios were examined instead of the 2:0.14 ratio, which could not be fitted. Therefore, the emitted ratio for the sample collected on March 1415 was 10:0.14 for ${ }^{89} \mathrm{Sr}:{ }^{90} \mathrm{Sr}$. The peak data for March 2021 indicated that a ratio of 9:0.14 fit perfectly. Table 2 in

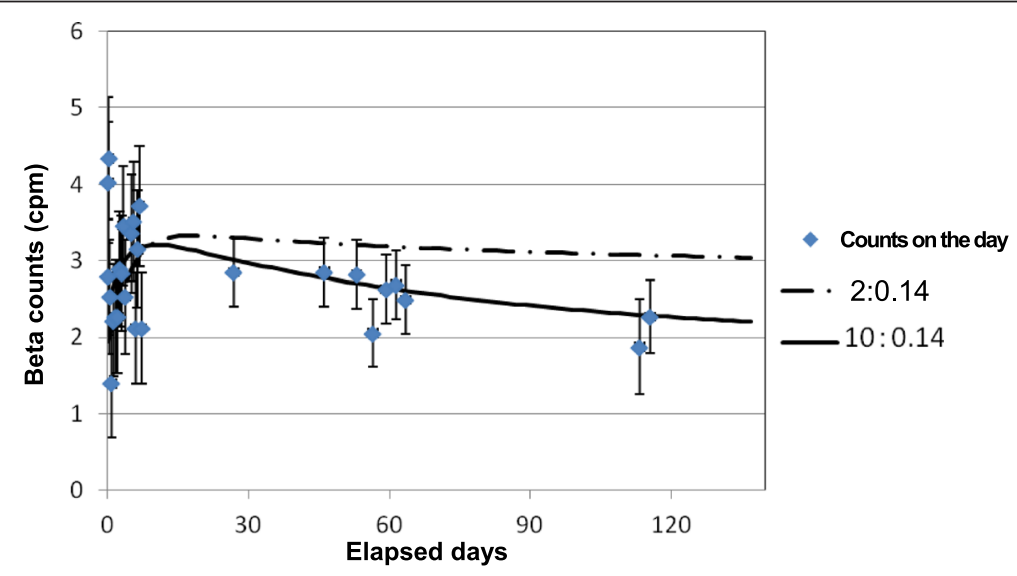

Fig. 10 Deconvolution of the ${ }^{89} \mathrm{Sr},{ }^{90} \mathrm{Sr}$ and ${ }^{90} \mathrm{Y}$ activities. It is possible to deconvolute radionuclides by measuring the temporal change in the total $\beta$-activity (cpm) of the purified radioSr source (March 14-15, 2011 sample). Elapsed days means the time after the radiochemical separation. An initial activity ratio of ${ }^{89} \mathrm{Sr} /{ }^{90} \mathrm{Sr}$ was assumed and applied to the curve fit as $2 / 0.14$ and 10/0.14. 
Table 3 Efficiency of ${ }^{137} \mathrm{Cs}$ extracted from air filter samples by heated concentrated nitric acid

\begin{tabular}{lccc}
\hline Sampling date and time (JST) & Before ext. ${ }^{137} \mathrm{Cs}(\mathrm{Bq})$ & After ext. ${ }^{137} \mathrm{Cs}(\mathrm{Bq})$ & Extraction efficiency (\%) \\
\hline March $1421 \mathrm{pm}$-March15 $9 \mathrm{am}$ & $243 \pm 0.7$ & $72 \pm 0.4$ & 70.4 \\
March $159 \mathrm{am}$-March $1515 \mathrm{pm}$ & $41 \pm 0.3$ & $7.4 \pm 0.12$ & 82.0 \\
March $1515 \mathrm{pm}$-March $1521 \mathrm{pm}$ & $20 \pm 0.2$ & $6.1 \pm 0.11$ & 69.5 \\
March $1521 \mathrm{pm}$-March $169 \mathrm{am}$ & $19 \pm 0.2$ & $0.51 \pm 0.04$ & 97.3 \\
March $169 \mathrm{am}$-March $179 \mathrm{am}$ & $9.2 \pm 0.19$ & $0.52 \pm 0.04$ & 94.3 \\
March $199 \mathrm{am}$-March $2021 \mathrm{pm}$ & $94.2 \pm 0.6$ & $0.20 \pm 0.03$ & 99.8 \\
March 2021 pm-March $219 \mathrm{am}$ & $423 \pm 0.9$ & $1.2 \pm 0.05$ & 99.7 \\
March 219 am-March $229 \mathrm{pm}$ & $30.8 \pm 0.24$ & $0.15 \pm 0.03$ & 99.5 \\
\hline
\end{tabular}

Air filter samples were subjected to heated conc. nitric acid extraction for Sr analysis. Cs-137 was measured to confirm the extraction efficiency. Samples shown as "nd" before extraction were excluded from the table. Some samples exhibited significantly lower extraction efficiencies of $70-80 \%$. Insoluble and refractory radioactive particles must have been incorporated in these samples

the Appendix 2 shows these fitting results. Therefore, the emission ratio of ${ }^{89} \mathrm{Sr} /{ }^{90} \mathrm{Sr}$ for both March $14-15$ and 20-21 was approximately 70 (10:0.14), which was five times bigger than what NISA 2011 had estimated.

The MEXT has reported ${ }^{89,90} \mathrm{Sr}$ in approximately 50 soil samples within $80 \mathrm{~km}$ of the FDNPP (MEXT 2011b). The decay data are corrected as of June 2011, and the activity ratio was reported to be in the range of 1.9-6.5 (average: 4). Another decay correction as of March 11, 2011 gives ${ }^{89} \mathrm{Sr} /{ }^{90} \mathrm{Sr}$ ratios of $7-24$ with an average of 15 . The ratio is not consistent with our results, and the fluctuation was large. The cause of the discrepancy and fluctuation is still unknown. The most likely explanation is that stable $\mathrm{Sr}$, already present in reactor materials or seawater components, absorbed neutrons and formed ${ }^{89} \mathrm{Sr}$. The extent of and fluctuation in mixing (inhomogeneity) might produce the discrepancy.

\section{Efficiency of acid extraction of ${ }^{137} \mathrm{Cs}$ from filter specimens} The rates at which ${ }^{137} \mathrm{Cs}$ could be extracted from the filter and aerosol samples using acid are shown in Table 3 in the Appendix 2. The samples collected on March 14-15 and 20-21 have different extraction rates, indicating that the ${ }^{137} \mathrm{Cs}$ in the sample from the March 14-15 was refractory to some extent (20$30 \%)$, even in a heated solution of nitric acid. This is possibly because of the difference in the physical and chemical nature of the radioactive aerosol. Thus, it is possible that the current radioSr concentration has been slightly underestimated (20-30\%) because of the low water dissolution rate of the radioactive material, especially for the March 14-15 sample.

As shown here, observations of the radioactive plume over Tsukuba at different times demonstrated that the ${ }^{89} \mathrm{Sr} /{ }^{90} \mathrm{Sr}$ ratio was almost constant, but the ${ }^{137} \mathrm{Cs} /{ }^{90} \mathrm{Sr}$ ratio and the extraction efficiency of ${ }^{137} \mathrm{Cs}$ with nitric acid differed. Moreover, it was shown earlier that the activity ratios among other $\gamma$-emitters differed (see Appendix 1).
These findings confirm that the characteristics of the aerosol particles that carried major radionuclides from the first plume differed from later advected radioactive plumes. Adachi et al. (2013) addressed this sort of contrast in the characteristics of the two plumes' radioactive aerosols in detail, and Abe et al. (2014) added more information. They documented the discovery of insoluble, glassy spherules containing radioCs and assumed that the major fraction came from the first event. Indeed, no such particles were detected in the later event. This should also affect the ratio of ${ }^{137} \mathrm{Cs} /{ }^{90} \mathrm{Sr}$ in the air, and evidence regarding this will be obtained in future work. In conclusion, the present results support the previous findings of less ${ }^{90} \mathrm{Sr}$ contamination than radioCs contamination from the FDNPP accident and indicate the necessity of further investigations of radioSr in the atmospheric environment.

\section{Abbreviations}

ATSDR: US Department of Health and Human Services, Public Health Service, Agency for Toxic Substances and Disease Registry; DOE: US Department of Energy; FDNPP: Fukushima Dai-ichi nuclear power plant; HYSPLIT: Hybrid Single Particle Lagrangian Integrated Trajectory Model; IAEA: International Atomic Energy Agency; JMA: Japan Meteorological Agency; KURRI: Kyoto University Research Reactor Institute; MANAL: Meso-regional objective analysis; MEXT: Ministry of Education, Culture, Sports, Science and Technology, Japan; MRI: Meteorological Research Institute, Japan; NASA: National Aeronautics and Space Administration, USA; NHM: The JMA/MRI non-hydrostatic meteorological model; NISA: The former Nuclear and Industrial Safety Agency, Japan Carriage Return; RAQM2: Regional Air Quality Model 2; SCJ: Science Council of Japan Carriage Return; TEPCO: Tokyo Electric Power Company.

\section{Competing interests}

The authors declare that they have no competing interests.

\section{Authors' contributions}

$\mathrm{YI}$ designed and supervised the study and summarized the manuscript. MK conducted the transport simulation and wrote that part of the manuscript. Both $\mathrm{Yl}$ and MK analyzed the data and helped in their interpretation. YZ helped conduct the sampling. KA and MM provided important suggestions for summarizing the work. They collaborated with the corresponding author in the preparation of the manuscript. All the authors read and approved the final manuscript. 


\section{Authors' information}

$\mathrm{YI}$ received his $\mathrm{PhD}$ degree in chemistry from the University of Tsukuba in 1987. From 1987 to 1991, he was at the National Institute of Radiological Sciences and studied radiochemical analysis and radioecology. He moved to the MRI in 1991 because of his scientific ambition to be involved in more global issues. His current interests are atmospheric aerosols and their precursors, including Asian dust and $\mathrm{PM}_{2.5}$, and their possible influences on climate, general environmental change, and other phenomena. He is working enthusiastically and is a member of several organizations, including the Japan Association of Aerosol Science and Technology, the Geochemical Society of Japan, the Japan Society of Nuclear and Radiochemical Sciences, the Meteorological Society of Japan, the Japan Radioisotope Association, the Japan Society of Analytical Chemistry, and the Japan Geoscience Union. He considers collaboration between observational researchers and modelers as a basic requisite in pursuing the geo- and environmental sciences. MK received his PhD from the Graduate School of Science at Kyoto University in 2005. Since then, he has been engaged in the development of chemical transport models coupled with regional-scale meteorological models at the Disaster Prevention Research Institute, Kyoto University, Research Center for Advanced Science and Technology, University of Tokyo, and currently, the MRI. His main research interest is elemental processes of chemistry and microphysics of airborne particles and its impacts on air quality, ecosystem, and climate.

YZ graduated Meteorological College in 1984 and worked at the Nagasaki Marine Observatory, Japan Meteorological Agency from 1984 to 1989. He has been studying atmospheric aerosols at the MRI since 1989 and received his PhD from Nagoya University in 2005.

KA received his PhD from Kobe University in 2005, worked at Arizona State University between 2005 and 2011 as a postdoctoral/faculty research associate, and is currently studying atmospheric aerosols at the MRI. MM received his PhD from Tohoku University in 1996, has worked at the MRI from 1985 to 2015, and finally holds the position of Senior Researcher for Research Affairs at the institute. Currently, he is working at Japan Meteorological Business Support Center.

\section{Acknowledgements}

The authors are deeply indebted to the following part-time and temporary staff members at the MRI: Chitsuko Takeda, Tokyo Nuclear Service Co. Ltd., and Kazue Inukai and Keiko Kamioka, currently at ATOX Co. Ltd. for the difficult work of analyzing samples and preparing samples measurements under an unusually severe accident situation; Hiroshi Sakou, Toru Kimura, and Sakae Mayama, ATOX Co. Ltd. for sampling, sample preparation, and general analysis; Wakari Iwai and Kazuma Nabeshima for radiochemical analysis of Sr isotopes and sample preparation, respectively; and Yuriko Kamiya, Kayo Yanagida, and Rina Mori for sampling, logistical support, figure preparation, and manuscript editing. Takeshi Ito helped with the trajectory analysis in the revised manuscript. The authors are also grateful to the following MRI academic colleagues: Hiroaki Naoe, Michio Aoyama (currently at Fukushima University), and Hiroshi Takahashi (currently at the Japan Meteorological Agency) for their help with sampling. Additionally, they acknowledge the assistance of Naoyuki Osada (currently at Okayama University) and Yuichi Oki (Kyoto University Research Reactor Institute) with low-background $\gamma$-ray measurements. The authors benefitted from discussions with Kazuyuki Kita (Ibaraki University) and Yuko Hatano (University of Tsukuba) regarding the re-suspension issue. Olivier Masson, IRSN, France, kindly gave critical comments on an early version of the manuscript, for which the authors are grateful. This study was financially supported by the former MEXT and current Nuclear Regulation Authority "Japanese Radioactivity Survey" fund and partially by the MEXT "Kakenhi" (a Grant-in-Aid for Scientific Research on Innovative Areas under the A01-1 and A01-2 research teams in the "Interdisciplinary Study on Environmental Transfer of Radionuclides from the Fukushima Daiichi NPP Accident (ISET-R; leader: Professor Yuichi Onda, University of Tsukuba)"; grant nos. 24110002 and 24110003) and the JSPS "Kakenhi" (leader Dr. Tsuyoshi T Sekiyama, MRI; grant no. 24340115). We gratefully acknowledge NOAA's ARL for providing the HYSPLIT transport and dispersion model and the READY website used in this study. The present paper was written and organized based on previous proceedings (Iwai et al. 2012; Igarashi et al. 2013a) and presentations at the ICAS, AMS, EGU, domestic meetings, and other settings (lgarashi et al. 2011, 2013b , 2013c) and the MRI home page (MRI 2011).

\section{Author details}

'Meteorological Research Institute, 1-1 Nagamine, Tsukuba, Ibaraki 305-0052, Japan. ${ }^{2}$ Present address: Japan Meteorological Business Support Center, Chiyoda-ku, Tokyo 101-0054, Japan.

Received: 16 March 2015 Accepted: 22 October 2015

Published online: 09 December 2015

\section{References}

Abe Y, lizawa Y, Terada Y, Adachi K, Igarashi Y, Nakai I. Detection of uranium and chemical state analysis of individual radioactive microparticles emitted from the Fukushima nuclear accident using multiple synchrotron radiation X-ray analyses. Anal Chem. 2014;86:8521-5. doi:10.1021/ac501998d.

Adachi K, Kajino M, Zaizen Y, Igarashi Y. Emission of spherical cesium-bearing particles from an early stage of the Fukushima nuclear accident. Sci Rep. 2013;3:2554. doi:10.1038/srep02554

Amano H, Akiyama M, Chunlei B, Kawamura T, Kishimoto T, Kuroda T, et al. Radiation measurements in the Chiba Metropolitan Area and radiological aspects of fallout from the Fukushima Dai-ichi Nuclear Power Plants accident. J Environ Radioact. 2012;111:42-52. doi:10.1016/j.jenvrad.2011.10.019.

Aoyama M. Evidence of stratospheric fallout of caesium isotopes from Chernobyl accident. Geophys Res Lett. 1988;15:327-30. doi:10.1029/GL015i004p00327.

Aoyama M, Hirose K. The temporal and spatial variation of ${ }^{137} \mathrm{Cs}$ concentration in the Western North Pacific and its marginal seas during the period from 1979 to 1988. J Environ Radioact. 1995;29:57-74. doi:10.1016/0265-931X(94)00050-7.

Aoyama M, Hirose K. Artificial radionuclides database in the Pacific Ocean: HAM database. Sci World J. 2004;4:200-15. doi:10.1100/tsw.2004.15.

Aoyama M, Hirose K, Suzuki Y, Inoue H, Sugimura Y. High level radioactive nuclides in Japan in May. Nature. 1986;321:819-20. doi:10.1038/321819a0.

Aoyama M, Hirose K, Sugimura Y. Deposition of gamma-emitting nuclides in Japan after the reactor-IV accident at Chernobyl. J Radioanal Nucl Chem. 1987;116:291-306. doi:10.1007/BF02035773.

Aoyama M, Hirose K, Sugimura Y. The temporal variation of stratospheric fallout derived from the Chernobyl accident. J Environ Radioact. 1991;13:103-15. doi:10.1016/0265-931X(91)90053-I.

Aoyama M, Ohara T, Komura K. Donen Tokai jiko niyoru houshasei sesiumu no Kanto heiya heno hirogari (Transport and diffusion of radioactive caesium to the Kanto plain by the PNC Tokai accident). Kagaku. 1999;69(1):16-21 (in Japanese).

Aoyama M, Hirose K, Igarashi Y. Re-construction and updating our understanding on the global weapons tests ${ }^{137} \mathrm{Cs}$ fallout. J Environ Monitor. 2006;8:431-8. doi:10.1039/B512601K

Aoyama M, Tsumune D, Hamajima Y. Distribution of ${ }^{137} \mathrm{Cs}$ and ${ }^{134} \mathrm{Cs}$ in the North Pacific Ocean: impacts of the TEPCO Fukushima-Daiichi NPP accident. J Radioanal Nucl Chem. 2012;296(1):535-9. doi:10.1007/s10967-012-2033-2.

Aoyama M, Uematsu M, Tsumune D, Hamajima Y. Surface pathway of radioactive plume of TEPCO Fukushima NPP1 released ${ }^{134} \mathrm{Cs}$ and ${ }^{137} \mathrm{Cs}$. Biogeosciences. 2013;10:3067-78. doi:10.5194/bg-10-3067-2013.

Chino M, Nakayama H, Nagai H, Terada H, Katata G, Yamazawa H. Preliminary estimation of release amounts of ${ }^{131}$ I and ${ }^{137} \mathrm{Cs}$ accidentally discharged from the Fukushima Daiichi Nuclear Power Plant into atmosphere. J Nucl Sci Technol. 2011:48:1129-34. doi:10.1080/18811248.2011.9711799.

Doi T, Masumoto K, Toyoda A, Tanaka A, Shibata Y, Hirose K. Anthropogenic radionuclides in the atmosphere observed at Tsukuba: characteristics of the radionuclides derived from Fukushima. J Environ Radioact. 2013;122:55-62. doi:10.1016/j.jenvrad.2013.02.001.

Ehhalt DH. Turnover times of ${ }^{137} \mathrm{Cs}$ and HTO in the troposphere and removal rates of natural particles and vapor. J Geophys Res. 1973;78:7076-86.

Estevan MT. Consequences of the Algeciras accident, and the Spanish system for the radiological surveillance and control of scrap and the products of its processing. In: Security of radioactive sources, proceedings of an international conference. Vienna Austria: IAEA; 2003. p. 357-62. 10-13 March 2003.

Garger EK, Kuzmenko Yl, Sickinger S, Tschiersch J. Prediction of the ${ }^{137} \mathrm{Cs}$ activity concentration in the atmospheric surface layer of the Chernobyl exclusion zone. J Environ Radioact. 2012;110:53-8. doi:10.1016/j.jenvrad.2012.01.017.

Haba H, Kanaya J, Mukai H, Kambara T, Kase M. One-year monitoring of air-borne radionuclides in Wako, Japan, after the Fukushima Dai-ichi nuclear power plant accident in 2011. Geochem J. 2012;46(4):271-8. Special Issue: Fukushima Review. 
Hatano $Y$, Hatano N. Formula for the resuspension factor and estimation of the date of surface contamination. Atmos Environ. 2003;37:3475-80. doi:10.1016/S1352-2310(03)00410-2.

Hernández-Ceballos MA, Hong GH, Lozano RL, Kim Yl, Lee HM, Kim SH, et al. Tracking the complete revolution of surface westerlies over Northern Hemisphere using radionuclides emitted from Fukushima. Sci Total Environ. 2012;438:80-5.

Hirose K. Fukushima Dai-ichi nuclear power plant accident: summary of regional radioactive deposition monitoring results. J Environ Radioact. 2012;111:13-7. doi:10.1016/j.jenvrad.2011.09.003.

Hirose K. Temporal variation of monthly ${ }^{137} \mathrm{Cs}$ deposition observed in Japan: effects of the Fukushima Daiichi nuclear power plant accident. Appl Radiat Isot. 2013;81:325-9. doi:10.1016/j.apradiso.2013.03.076.

Hirose K, Aoyama M. Present background levels of surface ${ }^{137} \mathrm{Cs}$ and ${ }^{239,240} \mathrm{Pu}$ concentrations in the Pacific. J Environ Radioact. 2003;69(1-2):53-60. doi:10.1016/S0265-931X(03)00086-9.

Hirose K, Sugimura Y, Katsuragi Y. ${ }^{90} \mathrm{Sr}$ and ${ }^{239+240} \mathrm{Pu}$ in the surface air in Japan: their concentrations and size distributions. Pap Met Geophys. 1986;37(4):255-69.

Hirose K, Takatani S, Aoyama M. Wet deposition of radionuclides derived from the Chernobyl accident. J Atmos Chem. 1993;17:61-71. doi:10.1007/BF00699114.

Hirose K, Amano H, Baxter MS, Chaykovskaya E, Chumichev VB, Hong GH, et al. Anthropogenic radionuclides in seawater in the East Sea/Japan Sea: results of the first-stage Japanese-Korean-Russian expedition. J Environ Radioact. 1999;43:1-13.

Hirose K, Igarashi Y, Aoyama M, Miyao T. Long-term trends of plutonium fallout observed in Japan. In: Kudo A (ed) Radioactivity in the environment Vol 1. pp 251-266. Plutonium in the environment proceedings of the second international symposium, Osaka, Japan, November 9-12, 1999. Amsterdam: Elsevier; 2001. doi:10.1016/\$1569-4860(01)80018-8.

Honda MC, Aono T, Aoyama M, Hamajima Y, Kawakami H, Kitamura M, et al. Dispersion of artificial caesium-134 and -137 in the western North Pacific one month after the Fukushima accident. Geochem J. 2012:46:e1-9.

Igarashi Y. Anthropogenic radioactivity in aerosol: a review focusing on studies during the 2000s. Jpn J Health Phys. 2009:44(3):313-23.

Igarashi Y, Otsuji-Hatori M, Hirose K. Recent deposition of ${ }^{90} \mathrm{Sr}$ and ${ }^{137} \mathrm{Cs}$ observed in Tsukuba. J Environ Radioact. 1996;31:157-69. doi:10.1016/0265-931X(96)88491-8.

Igarashi Y, Aoyama M, Miyao T, Hirose K, Komura K, Yamamoto M. Air concentration of radiocaesium in Tsukuba, Japan following the release from the Tokai waste treatment plant: comparisons of observations with predictions. Appl Radiat Isotopes. 1999a;50:1063-73. doi:10.1016/S0969-8043(98)00129-8.

Igarashi Y, Aoyama M, Miyao T, Hirose K, Tomita M. Anomalous ${ }^{90} \mathrm{Sr}$ deposition during the fall, 1995 at MRI, Tsukuba, Japan. J Radioanal Nucl Chem. 1999b;239:539-42. doi:10.1007/BF02349065.

Igarashi Y, Miyao T, Aoyama M, Hirose K, Sartorius H, Weiss W. Radioactive noble gases in the surface air monitored at MRI, Tsukuba, before and after the JCO accident. J Environ Radioact. 2000a:50:107-18.

Igarashi Y, Sartorius H, Miyao T, Weiss W, Fushimi K, Aoyama M, et al. ${ }^{85} \mathrm{Kr}$ and ${ }^{133}$ Xe monitoring at MRI, Tsukuba and its importance. J Envrion Radioactiv. 2000b;48:191-202. doi:10.1016/S0265-931X(99)00076-4.

Igarashi Y, Aoyama M, Hirose K, Miyao T, Nemoto K, Tomita M, et al. Resuspension: decadal monitoring time series of the anthropogenic radioactivity deposition in Japan. J Radiat Res. 2003:44:319-28.

Igarashi Y, Inomata Y, Aoyama M, Hirose K, Takahashi H, Shinoda Y, et al. Possible change in Asian dust source suggested by atmospheric anthropogenic radionuclides during the 2000s. Atmos Environ. 2009:43:2971-80.

Igarashi Y, Kajino M, Osada N, Oki Y, Takeda C. Aerosol radioactivity observed in Tsukuba during March 2011. Kyoto: ICAS2011 (IUPAC International Congress on Analytical Sciences); 2011.

Igarashi Y, Zaizen Y, Adachi K, Kajino M. Mikami M. Atmospheric pollution by the Fukushima accident: two years observations in Tsukuba. In: Bessho K, Tagami K, Takamiya K, Miura T, editors. Proceedings the 14th workshop on environmental radioactivity, pp 35-39 (in Japanese with English abstract). Tsukuba: High Energy Accelerator Research Organization; 2013a.

Igarashi Y, Kajino M, Zaizen Y, Mikami M. Observations of atmospheric radionuclides from the Fukushima nuclear accident in Tsukuba, Japan, American Meteorological Society 93rd annual meeting, Austin, Texas, Jan 2013. 2013b.

Igarashi Y, Kajino M, Zaizen Y, Adachi K, Mikami M, Kita K, et al. Atmospheric radionuclides from the Fukushima nuclear accident: two years observations in Tsukuba, Japan, the EGU general assembly 2013, Vienna, Austria, Apr 2013. 2013c. International Atomic Energy Agency. Environmental consequences of the Chernobyl accident and their remediation: twenty years of experience report of the Chernobyl Forum Expert Group "Environment". Vienna, Austria: 2006. ISBN 92-0-114705-8, ISSN 1020-6566
Iwai W, Igarashi Y, Nabeshima K. Observation of radioactivity of the atmospheric aerosol (radioactive Sr). In: Bessho K, Tagami K, Takamiya K, Miura T, editors. Proceedings the 13th workshop on environmental radioactivity. Tsukuba: High Energy Accelerator Research Organization; 2012. p. 102-7 (in Japanese with English abstract).

Janžekovič H, Križman MJ. Comparison of discharges of the nuclear accidents in Japan 2011 and Chernobyl 1986. In: Proceedings of the international conference nuclear energy for New Europe, Bovec, Slovenia, Sept 12-15, 2011. 2011.

Kajino M, Inomata Y, Sato K, Ueda H, Han Z, An J, et al. Development of the RAQM2 aerosol chemical transport model and predictions of the Northeast Asian aerosol mass, size, chemistry, and mixing type. Atmos Chem Phys. 2012;12:11833-56. doi:10.5194/acp-12-11833-2012.

Kanai Y. Monitoring of aerosols in Tsukuba after Fukushima Nuclear Power Plant incident in 2011. J Environ Radioact. 2012;111:33-7. doi:10.1016/ j.jenvrad.2011.10.011.

Kaneyasu N, Ohashi H, Suzuki F, Okuda T, Ikemori F. Sulfate aerosol as a potential transport medium of radiocesium from the Fukushima nuclear accident. Environ Sci Technol. 2012;46:5720-6.

Katata G, Ota M, Terada H, Chino M, Nagai H. Atmospheric discharge and dispersion of radionuclides during the Fukushima Dai-ichi Nuclear Power Plant accident. Part l: source term estimation and local-scale atmospheric dispersion in early phase of the accident. J Environ Radioact. 2012a;109:103-13.

Katata G, Terada H, Nagai H, Chino M. Numerical reconstruction of high dose rate zones due to the Fukushima Dai-ichi Nuclear Power Plant accident. J Environ Radioact. 2012b;111:2-12.

Katata G, Chino M, Kobayashi T, Terada H, Ota M, Nagai H, et al. Detailed source term estimation of the atmospheric release for the Fukushima Daiichi Nuclear Power Station accident by coupling simulations of atmospheric dispersion model with improved deposition scheme and oceanic dispersion model. Atmos Chem Phys Discuss. 2014;14:14725-832. doi:10.5194/acpd-14-14725-2014.

Katsuragi Y. A study of ${ }^{90} \mathrm{Sr}$ fallout in Japan. Pap Met Geophys. 1983;33(4):277-91. Kinoshita N, Sueki K, Sasa K, Kitagawa J, Ikarashi S, Nishimura T, et al. Assessment of individual radionuclide distributions from the Fukushima nuclear accident covering central-east Japan. Proc Natl Acad Sci U S A. 2011;108(49):19526-9. doi:10.1073/pnas.1111724108.

Komura K, Yamamoto M, Muroyama T, Murata Y, Nakanishi T, Hoshi M, et al. The JCO criticality accident at Tokai-mura, Japan: an overview of the sampling campaign and preliminary results. J Environ Radioactiv. 2000;50:3-14.

Kristiansen NI, Stohl A, Wotawa G. Atmospheric removal times of the aerosolbound radionuclides ${ }^{137} \mathrm{Cs}$ and ${ }^{131}$ I measured after the Fukushima Dai-ichi nuclear accident: a constraint for air quality and climate models. Atmos Chem Phys. 2012;12:10759-69.

Kusakabe M, Oikawa S, Takata H, Misonoo J. Spatiotemporal distributions of Fukushima-derived radionuclides in nearby marine surface sediments. Biogeosciences. 2013;10:5019-30. doi:10.5194/bg-10-5019-2013.

Maki T, Tanaka TY, Kajino M, Sekiyama T, Igaraashi Y, Mikami M. Radioactive nuclei emission analysis from Fukushima Daiichi Nuclear Power Plant by inverse model, Manuscript for 93rd American Meteorological Society annual meeting, Austin Texas U.S. 2013. (https:/ams.confex.com/ams/93Annual/ webprogram/Paper216873.html Accessed date: October 14, 2015)

Masson O. Private communication, Radioprotection Division, Environmental Radioactivity Study and Monitoring Department, Institute for Radiological Protection and Nuclear Safety, France. 2014

Masson O, Baeza A, Bieringer J, Brudecki K, Bucci S, Cappai M, et al. Tracking of air-borne radionuclides from the damaged Fukushima Dai-ichi nuclear reactors by European networks. Environ Sci Technol. 2011;45:7670-7.

Masumoto Y, Miyazawa Y, Tsumune D, Kobayashi T, Estournel C, Marsaleix P, et al. Oceanic dispersion simulation of Cesium-137 from Fukushima Dai-ichi Nuclear Power Plant. Elements. 2012;8:207-12.

Maxwell RM, Anspaugh LR. An improved model for prediction of resuspension. Health Phys. 2011;101:722-30. doi:10.1097/HP.0b013e31821ddb07.

Meteorological Research Institute (MRI). Tokyo Denryoku Fukushima Dai-ichi Genshiryoku Hatsudensho Jiko nitomonau houshaseibusshitsu no iryuukakusan nitsuite (On the transport and diffusion of radioactive materials by the Fukushima Dai-ichi Nuclear Power Station accident)" (in Japanese). 2011. http://www.mrijma.go.jp/Topics/H23/H23_tohoku-taiheiyo-oki-eq/1107fukushima.html.

Ministry of Education, Culture, Sports, Science and Technology (MEXT). Monbu Kagaku-sho oyobi lbaraki-ken niyoru kokuki monitaringu no sokutei kekka no shuusei nitsuite (On the correction of the aerial monitoring results conducted by MEXT and Ibaraki prefecture) dated August 31, 2011 (in Japanese). 2011a. http://radioactivity.nsr.go.jp/ja/contents/5000/4933/24/1940_0831.pdf. 
Ministry of Education, Culture, Sports, Science and Technology (MEXT). Monbu Kagaku-sho ni yoru, purutoniumu, sutoronchiumu no kakushu bunseki no kekka nitsuite (On the analytical results for Pu and Sr by MEXT) dated September 30, 2011 (in Japanese). 2011b. http://radioactivity.nsr.go.jp/ja/ contents/6000/5048/24/5600_110930_rev130701.pdf.

Ministry of Education, Culture, Sports, Science and Technology, Results of Air-borne Monitoring by the Ministry of Education, Culture, Sports, Science and Technology and the U.S. Department of Energy (MEXT \& USDOE). 2011. dated May 6, 2011.

Miyake $Y$. The artificial radioactivity in rain water observed in Japan, from autumn 1954 to spring 1955. Pap Met Geophys. 1954;6(1):26-31.

Miyake $Y$, Sugiura Y, Kameda K. On the distribution of radioactivity in the sea: around Bikini Atoll in June, 1954. Pap Met Geophys. 1955;5:253-62.

Miyake Y, Saruhashi K, Katsuragi Y, Kanazawa T. Penetration of ${ }^{90} \mathrm{Sr}$ and ${ }^{137} \mathrm{Cs}$ in deep layers of the Pacific and vertical diffusion rate of deep water. J Radiat Res. 1962;3(3):141-7.

Miyake Y, Samhashi K, Katsuragi Y, Kanazawa T, Tsunogai S. Deposition of Sr-90 and Cs-137 in Tokyo through the end of July 1963. Pap Met Geophys. 1963;14:58-65.

Miyake Y, Katsuragi Y, Sugimura Y. Plutonium fallout in Tokyo. Pap Met Geophys. 1975;26(1):1-8.

Miyake Y, Saruhashi K, Sugimura Y, Kanazawa T, Hirose K. Contents of ${ }^{137} \mathrm{Cs}$, plutonium and americium isotopes in the Southern Ocean waters. Pap Met Geophys. 1988;39:95-113.

Miyao T, Hirose K, Aoyama M, Igarashi Y. Trace of the recent deep water formation in the Japan Sea deduced from historical ${ }^{137} \mathrm{Cs}$ data. Geophys Res Lett. 2000;27(22):3731-4.

Morino Y, Ohara T, Nishizawa M. Atmospheric behavior, deposition, and budget of radioactive materials from the Fukushima Daiichi nuclear power plant in March 2011. Geophys Res Lett. 2011;38:L00G11. doi:10.1029/2011GL048689.

Nuclear and Industrial Safety Agency (NISA). Houshasei bussitsu houshutsuryo deta no ichibu ayamari nitsuite (On a partial mistake in emission inventory estimate of radioactive materials) dated October 20, 2011 (in Japanese). 2011. http://warp.ndl.go.jp/info:ndljp/pid/6086248/www.meti.go.jp/press/2011/10/ 20111020001/20111020001.pdf.

Otsuji-Hatori M, Igarashi Y, Hirose K. Preparation of a reference fallout material for activity measurements. J Environ Radioact. 1996;31:143-55.

Petters MD, Kreidenweis SM. A single parameter representation of hygroscopic growth and cloud condensation nucleus activity. Atmos Chem Phys. 2007;7:1961-71. doi:10.5194/acp-7-1961-2007.

Povinec PP, Gera M, Holý K, Hirose K, Lujaniené G, Nakano M, et al. Dispersion of Fukushima radionuclides in the global atmosphere and the ocean. Appl Radiat Isot. 2013a;81:383-92.

Povinec PP, Aoyama M, Biddulph D, Breier R, Buesseler K, Chang CC, et al. Cesium, iodine and tritium in NW Pacific waters: a comparison of the Fukushima impact with global fallout. Biogeosciences. 2013b;10:5481-96. doi:10.5194/bg-10-5481-2013.

Saito K, Ishida J, Aranami K, Hara T, Segawa T, Narita M, et al. Nonhydrostatic atmospheric models and operational development at JMA. J Meteorol Soc Jpn. 2007:85B:271-304. doi:10.2151/jmsj.85B.271.

Sanada Y, Sugita T, Nishizawa Y, Kondo A, Torii T. The aerial radiation monitoring in Japan after the Fukushima Daiichi nuclear power plant accident. Progress in Nuclear Science and Technology. 2014;4:76-80.

Schwantes JM, Orton CR, Clark RA. Analysis of a nuclear accident: fission and activation product releases from the Fukushima Daiichi Nuclear Facility as remote indicators of source identification, extent of release, and state of damaged spent nuclear fuel. Environ Sci Technol. 2012;46(16):8621-7. doi:10.1021/es300556m.

Sectional Committee on Nuclear Accident Committee on Comprehensive Synthetic Engineering, Science Council of Japan (SCJ). Report "A review of the model comparison of transportation and deposition of radioactive materials released to the environment as a result of the Tokyo Electric Power Company's Fukushima Daiichi Nuclear Power Plant Accident" dated September 2, 2014. 2014. http://www.scj.go.jp/en/report/index.html.

Sekiyama T, Kunii M, Kajino M, Shimbori T. Horizontal resolution dependence of atmospheric simulations of the Fukushima nuclear accident using 15-km, 3-km, and 500 m grid models. J Meteor Soc Japan. 2015;93(1):49-64. doi:10.2151/jmsj.2015-002.

Stohl A, Seibert P, Wotawa G, Arnold D, Burkhart JF, Eckhardt S, et al. Xenon-133 and caesium-137 releases into the atmosphere from the Fukushima Dai-ichi Nuclear Power Plant: determination of the source term, atmospheric dispersion, and deposition. Atmos Chem Phys. 2012;12:2313-43. doi:10.5194/acp-12-2313-2012.
Takemura T, Nakamura H, Takigawa M, Kondo H, Satonuma T, Miyasaka T, et al. A numerical simulation of global transport of atmospheric particles emitted from the Fukushima Daiichi Nuclear Power Plant. Scientific Online Letters on the Atmosphere (SOLA). 2011;7:101-4.

Tanaka TY. Numerical simulation of global dispersion of radionuclides. Wind Engineers JAWE. 2013;38(4):388-95 (in Japanese).

Tanihata I. Sampling and mapping of soil contamination and what we have learn from it. Radioisotopes. 2013;62:724-40 (in Japanese).

Terada H, Katata G, Chino M, Nagai H. Atmospheric discharge and dispersion of radionuclides during the Fukushima Dai-ichi Nuclear Power Plant accident. Part II: verification of the source term and analysis of regional-scale atmospheric dispersion. J Environ Radioact. 2012;112:141-54. doi:10.1016/j.jenvrad.2012.05.023.

Tokyo Electric Power Company (TEPCO). Estimation of radioactive material released to the atmosphere during the Fukushima Daiichi NPS Accident dated May 2012. 2012. http://www.tepco.co.jp/en/press/corp-com/release/ betu12_e/images/120524e0205.pdf.

Torii T, Sugita T, Okada CE, Reed MS, Blumenthal DJ. Enhanced analysis methods to derive the spatial distribution of ${ }^{131} \mid$ deposition on the ground by air-borne surveys at an early stage after the Fukushima Daiichi Nuclear Power Plant accident. Health Phys. 2013;105(2):192-200.

Tsumune D, Tsubono T, Aoyama M, Uematsu M, Misumi K, Maeda Y, et al. One-year, regional-scale simulation of ${ }^{137} \mathrm{Cs}$ radioactivity in the ocean following the Fukushima Dai-ichi Nuclear Power Plant accident. Biogeosciences. 2013;10:5601-17. doi:10.5194/bg-10-5601-2013.

Tsuruta H, Oura Y, Ebihara M, Ohara T, Nakajima T. First retrieval of hourly atmospheric radionuclides just after the Fukushima accident by analyzing filter-tapes of operational air pollution monitoring stations. Sci Rep. 2014:4:6717. doi:10.1038/srep06717.

U.S. Department of Energy (USDOE). 2013. http://energy.gov/situation-japanupdated-12513

U.S. Department of Health and Human Services, Public Health Service, Agency for Toxic Substances and Disease Registry (ATSDR2004Cs). Toxicological Profile for Cesium. 2004. http://www.atsdr.cdc.gov/ToxProfiles/tp157.pdf.

U.S. Department of Health and Human Services, Public Health Service, Agency for Toxic Substances and Disease Registry (ATSDR2004Sr). Toxicological Profile for Strontium. 2004. http://www.atsdr.cdc.gov/ToxProfiles/tp159.pdf.

Winiarek V, Bocquet M, Saunier O, Mathieu A. Estimation of errors in the inverse modeling of accidental release of atmospheric pollutant: Application to the reconstruction of the cesium-137 and iodine-131 source terms from the Fukushima Daiichi Power Plant. J Geophys Res. 2012;117, D05122. doi:10.1029/2011JD016932.

Yamamoto M, Takada T, Nagao S, Koike T, Shimada K, Hoshi M, et al. An early survey of the radioactive contamination of soil due to the Fukushima Dai-ichi Nuclear Power Plant accident, with emphasis on plutonium analysis. Geochem J. 2012:46:341-53.

Yoshida N, Kanda J. Tracking the Fukushima radionuclides. Science. 2012;336:1115-6. doi:10.1126/science.1219493.

Yoshida N, Takahashi Y. Land-surface contamination by radionuclides from the Fukushima Daiichi Nuclear Power Plant accident. Elements. 2012;8:201-6. doi:10.2113/gselements.8.3.201.

Zhang W, Bean M, Benotto M, Cheung J, Ungar K, BAhier B. Development of a new aerosol monitoring system and its application in Fukushima nuclear accident related aerosol radioactivity measurement at the CTBT radionuclide station in Sidney of Canada. J Environ Radioactiv. 2011;102:1065-9. doi:10.1016/j.jenvrad.2011.08.007.

\section{Submit your manuscript to a SpringerOpen ${ }^{\circ}$ journal and benefit from:}

- Convenient online submission

Rigorous peer review

- Immediate publication on acceptance

- Open access: articles freely available online

- High visibility within the field

- Retaining the copyright to your article

Submit your next manuscript at $>$ springeropen.com 